\title{
El financiamiento político en América latina. Entre la leche materna y el veneno
}

\author{
Political Financing in Latin America: \\ Between Mother's Milk and Poison
}

\section{Kevin Casas* Daniel Zovatto**}

\section{Sumario:}

I. El financiamiento político: entre la leche materna y el veneno

II. ¿Cuáles son los riesgos? La experiencia de América Latina

III. ¿Qué hacer? Instrumentos de regulación y experiencia comparada

IV. Lecciones sobre la reforma del financiamiento político

V. ¿Hacia dónde ir? Algunas propuestas de reforma

VI. Bibliografía

* Secretario de asuntos políticos de la Organización de los Estados Americanos.

** Director regional para América Latina y el Caribe de IDEA Internacional.

Recibido: 23 de abril de 2012

Aceptado: 25 de mayo de 2012

D. R. (C 2012. Universidad Nacional Autónoma de México-Instituto de Investigaciones Jurídicas. 


\section{Resumen:}

La expansión de la democracia, la creciente complejidad de los procesos electorales y la conciencia de los riesgos que la corrupción supone para la viabilidad de los sistemas democráticos, han situado al financiamiento de la actividad política en el centro de la discusión pública en todo el mundo. Las siguientes páginas discuten, en primer lugar, los riesgos que comporta el tema del financiamiento político para la democracia en América Latina; en segundo lugar, los distintos instrumentos normativos disponibles y las lecciones - casi siempre tentativas- que enseña la experiencia latinoamericana e internacional sobre sus efectos, y en tercer lugar, presenta algunas reflexiones prácticas para viabilizar las propuestas de regulación y aumentar sus probabilidades de éxito. El texto, lejos de ofrecer conclusiones definitivas, busca abrir una discusión y aumentar las posibilidades de que los sistemas políticos latinoamericanos lleguen a tiempo para regular adecuadamente el delicado papel del dinero en la vida democrática.

\section{Abstract:}

The expansion of democracy, the growing complexity of electoral processes and awareness of the risks posed to the feasibility of democratic systems by corruption have placed financing of political activities at the core of public discussion around the world. The following pages discuss (1) the risks entailed by political financing for democracy in Latin America; (2) the various regulating instruments available, and the lessons learned -almost always tentatively- from Latin American and international experiences about their effects; and (3) practical considerations involved in making regulation proposals feasible, increasing their potential for success. Although it does not offer definite conclusions, the text seeks to open a discussion and increase the possibilities for Latin American political systems to properly regulate the sensitive role of money in democratic life.

Palabras clave: financiamiento político, regulación, gasto electoral y transparencia.

Descriptors: political financing, regulation, electoral expenditure and transparency. 


\section{El financiamiento político: entre la leche materna y el veneno}

"La relación entre el dinero y la política se ha convertido en uno de los grandes problemas del gobierno democrático", con esta frase abrió James Kerr Pollock su pionero volumen sobre las prácticas de financiamiento político en Gran Bretaña, Alemania y Francia, publicado en 1932. Tal aseveración, así como su llamado a la opinión pública a entender que "una vida política saludable no es posible en tanto el uso del dinero permanezca sin controles", son más veraces en la actualidad que en el propio tiempo de Pollock. ${ }^{1}$ La expansión de la democracia, la creciente complejidad de los procesos electorales y la conciencia de los riesgos que la corrupción supone para la viabilidad de los sistemas democráticos, han situado al financiamiento de la actividad política en el centro de la discusión pública en todo el mundo. El tema ha adquirido un perfil global y urgente.

En la base de ese interés hay un hecho ineludible: si bien la democracia no tiene precio, sí tiene un costo de funcionamiento. ${ }^{2}$ El uso de recursos económicos es un elemento imprescindible para la competencia democrática. Más que una patología de la democracia - como frecuentemente se le presenta en la discusión pública - el financiamiento político es parte de la normalidad y la salud de la vida democrática. Es innegable, sin embargo, que el dinero es capaz de introducir distorsiones importantes en el proceso democrático. Su desigual distribución incide, en primer lugar, sobre las posibilidades reales disfrutadas por los partidos y los candidatos para llevar su mensaje a los votantes. En segundo lugar, su posesión confiere a los individuos y a los grupos sociales una posibilidad diferenciada de participar en las elecciones y ejercer su influencia sobre los candidatos y los partidos, a través de sus contribuciones. Esto es de importancia crítica para la democracia. Cuando el poder político simplemente es un espejo del poder económico, el principio de "una persona, un voto" pierde su significado y la democracia deja de ser, en las palabras de Elmer Schattschnei-

1 Pollock, James Kerr, Money and Politics Abroad, Nueva York, Alfred A. Knopf, 1932, p. 328.

2 Griner, Steven y Zovatto, Daniel (eds.), De las normas a las buenas prácticas: el desafío del financiamiento político en América Latina, San José, OEA-IDEA, 2004, p. 298. 
der, un "sistema de poder alternativo, capaz de compensar el poder económico". ${ }^{3}$ En tercer lugar, los procesos de recaudación de fondos ofrecen obvias oportunidades para la articulación de intercambios entre los donantes privados y los tomadores de decisiones públicas, o, cuando menos, para la continua aparición de conflictos de intereses para estos últimos.

Así, pues, si su utilización no es regulada o es mal regulada, el dinero puede amenazar la legitimidad de los procesos y las prácticas democráticas, esto es la percepción de los ciudadanos de que las elecciones y los gobiernos democráticos reflejan aproximadamente sus demandas e intereses. La lapidaria frase del político estadounidense Jesse "Big Daddy" Unruh, que alguna vez sentenció que "el dinero es la leche materna de la política", cuenta, así, sólo una parte de la verdad. Lo cierto es que esa leche tiene elementos importantes de toxicidad, que es preciso eliminar o, al menos, controlar si no han de destruir el organismo democrático.

Estas preocupaciones son particularmente pertinentes en América Latina. Es la nuestra una región que presenta asombrosas desigualdades en la distribución de recursos económicos, iniquidades que inevitablemente crean sesgos en los procesos democráticos. Es también una región donde la presencia del crimen organizado - particularmente el narcotráfico- es una realidad indiscutible, que moviliza miles de millones de dólares al año y es, por ello, capaz de corromper y subvertir las instituciones democráticas. Regular el financiamiento político en América Latina es de vital importancia para la preservación de la democracia; los sistemas políticos de la región en general lo han entendido así, como lo sugiere la profusión de esfuerzos regulatorios intentados en las últimas dos décadas. Por más que sus resultados hayan sido frecuentemente decepcionantes, esa proliferación de esfuerzos es un signo de desarrollo democrático: mucho más consolidadas que los sistemas democráticos en otras regiones, las democracias latinoamericanas están en condiciones de abordar temas de alta complejidad como la regulación del financiamiento político, un asunto irresuelto aun en las democracias más desarrolladas.

Las siguientes páginas son ante todo un inventario, en un triple sentido: en primer lugar, de los riesgos que comporta el tema del financia-

3 Schattschneider, E. E., The Semi-Sovereign People, Fort Worth, Harcourt Brace Jovanovich College Publishers, 1975 [1960], p. 119. 
miento político para la democracia en América Latina; en segundo lugar, de los distintos instrumentos normativos disponibles y las lecciones - casi siempre tentativas - que enseña la experiencia latinoamericana e internacional sobre sus efectos; en tercer lugar, de algunas reflexiones prácticas para viabilizar las propuestas de regulación y aumentar sus probabilidades de éxito.

El texto es, así, animado por una intención eminentemente práctica, más que académica, aunque muy conscientes estemos de la urgencia de echar a andar una rigurosa agenda de investigación empírica que sitúe el tema en el centro de las ciencias políticas y permita iluminar su discusión pública. Lejos de ofrecer conclusiones definitivas, estas páginas buscan abrir una discusión y aumentar las posibilidades de que los sistemas políticos latinoamericanos lleguen a tiempo para regular adecuadamente el delicado papel del dinero en la vida democrática.

\section{II. ¿Cuáles son los riesgos? La experiencia de América Latina}

Si abordar adecuadamente la regulación del financiamiento político es una tarea urgente para las democracias en América Latina, ello se debe a que en las últimas tres décadas de vida democrática los países latinoamericanos han mostrado, con notable exuberancia, la gama de riesgos que implica la ausencia de una regulación efectiva de esta materia. Al igual que en otras latitudes — desde Israel hasta Japón, pasando por los Estados Unidos y Alemania- los recurrentes escándalos relacionados con el financiamiento político han hecho tambalear gobiernos en la región, al tiempo que han debilitado a los partidos políticos y erosionado la confianza de los ciudadanos en las instituciones democráticas. Cinco modalidades de riesgo lucen particularmente serias, además de recurrentes en el subcontinente. Serán ilustradas a continuación con algunos ejemplos.

\section{Utilización de financiamiento espurio o ilegal}

El financiamiento privado constituye un recurso legítimo y necesario para los partidos políticos y sus candidatos, con sus virtudes y peligros. 
Entre aquellas, cabe destacar que permite a los partidos políticos afinar sus puentes de contacto con la sociedad. Sin embargo, la posibilidad de recaudar fondos privados para financiar actividades políticas abre un abanico de riesgos considerable para la democracia. El primero y más serio de ellos es la posibilidad de utilizar para fines políticos dinero originado en actividades delictivas o ilegales.

En el caso de América Latina el mayor peligro es la posibilidad de que el narcotráfico y, en general, el crimen organizado penetren las instancias políticas para comprar impunidad mediante el financiamiento de campañas. ${ }^{4}$ No es esta, en absoluto, una posibilidad teórica. Los casos de las campañas de los ex presidentes Jaime Paz Zamora en Bolivia, Ernesto Samper en Colombia, y Ernesto Pérez Balladares en Panamá, todas durante la década de los noventa, son tan solo algunos de los más notables ejemplos que registra la región de penetración del narcotráfico en las campañas políticas. ${ }^{5}$ Estos ejemplos son apenas la parte más visible de un fenómeno mucho más extendido y perturbador, que presenta particulares riesgos en países como México, Colombia y Brasil, en los que las grandes campañas nacionales son complementadas por una vigorosa actividad electoral a nivel subnacional. ${ }^{6}$ Cabe señalar, en el mismo sentido, el riesgo de que los procesos de descentralización política emprendidos en casi toda la región faciliten la captura de las instituciones por parte del crimen organizado, habida cuenta del costo generalmente limitado de las campañas locales.

4 Un análisis de la relación entre financiamiento y corrupción política en América se encuentra en Griner, Steven y Zovatto, Daniel (eds.), De las normas a las buenas prácticas: el desafío del financiamiento político en América Latina, cit., pp. 299-302.

Mayorga, René, "El financiamiento de los partidos políticos en Bolivia", en Castillo, Pilar del y Zovatto, Daniel (eds.), La financiación de la política en Iberoamérica, San José, IIDH-CAPEL, 1998, p. 35; Jordan, David C., Drug Politics: Dirty Money and Democracies, Norman, University of Oklahoma Press, 1999, pp. 158-162; Vargas, Mauricio et al., El presidente que se iba a caer: Diario secreto de tres periodistas sobre el 8000, Bogotá, Planeta, 1996; Casas Zamora, "Financiamiento de campañas en Centroamérica y Panamá", Cuadernos de CAPEL, San José, núm. 48, 2003, p. 46; “Drugs are Back”, The Economist, 25 de mayo de 1996, y “Well I Never, Says the President", The Economist, 29 de junio de 1996.

6 Por ejemplo, en los meses previos a las elecciones legislativas de 2009 en México hubo por al menos dos casos de precandidatos legislativos (uno en el estado de Chihuahua y otro en el Estado de México) que fueron ligados al crimen organizado por reportes de prensa. Véase "Héctor Murguía: los narcos en casa", El Universal, México, 27 de marzo de 2009; "Registran candidatura de Héctor Murguía”, El Diario, Ciudad Juárez, 23 de abril de 2009. 
El narcotráfico y el crimen organizado plantean riesgos de particular intensidad para los procesos políticos, pero no es el único peligro. La financiación de campañas de alcaldes y diputados por parte de organizaciones paramilitares en Colombia en la última década, la vasta operación de financiamiento ilegal puesta en movimiento por el ex presidente Fernando Collor de Mello en Brasil, la desviación ilegal de fondos de la empresa petrolera estatal Pemex a la campaña del Partido Revolucionario Institucional y la recepción de fondos prohibidos del exterior al Partido Acción Nacional en el año 2000 en México, así como el envío secreto de US\$800000 en una maleta proveniente de Venezuela a la campaña de la presidenta Cristina Fernández en Argentina, configuran otros tantos ejemplos de la enorme gama de modalidades que ha asumido la utilización de fuentes de financiamiento cuestionables en las campañas del subcontinente. ${ }^{7}$

\section{La compra de influencia y los conflictos de interés}

Como se dijo más arriba, aun en los casos en que los recursos para la actividad partidaria y electoral no provienen de fuentes cuestionables ni son obtenidos por vías ilegales, es claro que las contribuciones privadas pueden comprometer el interés público y, en casos extremos, "privatizar" la toma de decisiones por parte de los funcionarios públi$\cos ^{8}{ }^{8}$ Eso dependerá, entre otros factores, de la cuantía de las contri-

7 Geddes, Barbara y Ribeiro-Neto, Artur, "Institutional Sources of Corruption in Brazil”, Third World Quarterly, vol. 13, núm. 4, 1992, p. 646; Kinzo, María D’Alva, "Funding Parties and Elections in Brazil", en Burnell, Peter y Ware, Alan (eds.), Funding Democratization, Manchester, Manchester University Press, 1998, p. 135, n. 23; Córdova, Lorenzo y Murayama, Ciro, Elecciones, dinero y corrupción: Pemexgate y Amigos de Fox, México, Cal y Arena, 2006; "El 'Pemexgate', una novela de no-ficción”, Proceso, 13 de octubre de 2002; "Caso maletín: cuatro detenidos en EE. UU., BBC Mundo.com, 13 de diciembre de 2007; "Maletín: apuntan al gobierno venezolano", BBC Mundo.com, 17 de octubre de 2008; "Conviction in Spy Case Over Cash-Filled Suitcase", The New York Times, 3 de noviembre de 2008. El caso de la presidenta Fernández en Argentina, remite a una patología con una larga tradición en la región: el financiamiento de partidos o candidatos por parte de gobiernos extranjeros, desde la antigua Unión Soviética hasta Taiwán. Véase al respecto el análisis de los casos de Uruguay y Costa Rica en Casas Zamora, Paying for Democracy: Political Finance and State Funding for Parties, Colchester, European Consortium for Political Research, 2005.

${ }^{8}$ Griner, Steven y Zovatto, Daniel (eds.), De las normas a las buenas prácticas: el desafío del financiamiento político en América Latina, cit., 2004. Estos autores destacan las 
buciones, de la transparencia con que manejen y del grado de discrecionalidad con que operen los tomadores de decisión. En el mejor de los casos, como lo han mostrado las investigaciones en los Estados Unidos, Costa Rica y Uruguay, las donaciones privadas facilitan considerablemente el acceso de los donantes a los tomadores de decisión, sin que necesariamente condicionen el contenido de sus determinaciones. ${ }^{9}$ En palabras utilizadas por la célebre sentencia de Buckley vs. Valeo en el contexto estadounidense, las contribuciones privadas no sólo pueden afectar los procesos democráticos por los intercambios corruptos a los que efectivamente den lugar, sino también por la apariencia de corrupción que con frecuencia generan. ${ }^{10}$

No es casual, por ello, que se haya detectado la presencia dominante de las empresas de construcción en el financiamiento de campañas en Brasil y Costa Rica, o de la empresa concesionaria de las actividades de lotería y quinielas en Uruguay, actividades todas ellas fuertemente dependientes de los contratos estatales o la regulación pública. ${ }^{11}$ Más relevante aún es el caso de los medios de comunicación privados, que a través de las tarifas diferenciadas que ofrecen a los partidos y candidatos, han devenido en un crucial donante en especie - acaso el mayor de todos- en algunos países de la región. Los casos de Uruguay, Costa Rica, Guatemala y México han sido debidamente documentados no sólo como situaciones de potencial colusión entre los propietarios de los medios y los funcionarios encargados de regular las frecuencias del espectro electromagnético, sino también como instancias de palpable inequidad por el acceso diferenciado a los medios concedido a candidatos y partidos durante las campañas electorales. ${ }^{12}$

figuras de cohecho (pagos a funcionarios por parte de contratistas del Estado en retribución por favores recibidos), y cohecho anticipado (la aceptación de dinero de personas o empresas a cambio de promesas y/o favores ilícitos en caso de acceder a puestos públicos), como algunas de las principales manifestaciones de la relación entre financiamiento político y corrupción (p. 299).

9 Sorauf, Frank J., Inside Campaign Finance: Myths and Realities, New Haven, Yale University Press, 1992, pp. 164-171; Casas Zamora, Paying for Democracy..., cit., p. 226.

10 Véase texto de la sentencia en Corrado, Anthony et al. (eds.), Campaign Finance Reform: A Sourcebook, Washington D. C., Brookings Institution Press, 1997, pp. 67-77.

${ }^{11}$ Kinzo, María D’Alva, "Funding parties and elections in Brazil", en Burnell, Peter y Ware, Alan (eds.), Funding Democratization, Manchester, Manchester University Press, 1998, pp. 130 y 131; Casas Zamora, Paying for Democracy..., cit., pp. 137 y 181.

12 Casas Zamora, Paying for Democracy..., cit., pp. 137-140 y 181-183; Transparency International, Global Corruption Report- 2004, Londres, Pluto Press, 2004, pp. 49 y 50; 


\section{Las iniquidades electorales graves}

Aunque sería necio sostener que la posesión de recursos económicos por parte de candidatos y partidos es capaz de determinar por sí misma los resultados electorales, es obvio que sí es capaz de crear significativas barreras de entrada al proceso electoral para ciertos grupos. Asimismo, una distribución de recursos marcadamente desigual puede crear una apariencia de iniquidad capaz de afectar la legitimidad de los resultados electorales.

Los ejemplos abundan en la región: desde la gran disparidad documentada en el financiamiento de las opciones políticas de izquierda con respecto al financiamiento de partidos más conservadores en países como México, Uruguay o Costa Rica, hasta el caso extremo de la elección de 1990 en Perú, en el que el gasto en publicidad del candidato más apegado al statu quo, el escritor Mario Vargas Llosa, superó por un factor de 56 a 1 las erogaciones incurridas por la campaña de Alberto Fujimori. ${ }^{13}$

Aún más serios son los casos en que las iniquidades económicas se combinan con otro factor distorsionante: el uso de los recursos del Estado para favorecer al partido o candidato oficial. Ello puede ir desde lo más sutil y difícilmente detectable - como la asignación de publicidad estatal en medios de comunicación como forma de presionar el comportamiento periodístico- hasta formas mucho más obvias $\mathrm{y}$, generalmente, prohibidas por la ley en los sistemas democráticos. Aunque el tema forma parte habitual del prontuario de alegatos de los partidos de oposición en casi toda la región, los casos de las elecciones presidenciales y referéndums en Venezuela en los últimos años, y en algunos sentidos la contienda presidencial en México en 2006, pueden ser mencionados como ejemplos en los que prima facie las acusaciones no han estado desprovistas de mérito. ${ }^{14}$

Arredondo Ramírez, Pablo, "Los medios de comunicación y la contienda electoral", Renglones, núm. 46, agosto-noviembre de 2000; Gómez Castellanos, Rodolfo, Mercadotecnia política: uso y abuso en los procesos electorales, México, Universidad Autónoma de Baja California, 2006, pp. 103-108.

${ }_{13}$ Miró Quesada, Francisco, "Financiamiento de partidos políticos y las campañas electorales en el Perú", en Castillo, Pilar del y Zovatto, Daniel (eds.), La financiación de la política en Iberoamérica, San José, IIDH-CAPEL, 1998, p. 481.

${ }_{14}$ El uso y abuso electoral de los recursos estatales por parte de quienes están en el poder es un extendido fenómeno en todo el mundo en desarrollo, aunque en muy distintos 
Nada de esto es bueno para la democracia. Sin embargo, algunos de los casos citados contienen una advertencia fundamental: las disparidades detectadas no impidieron el triunfo de Fujimori en Perú, el ascenso electoral y eventual triunfo del Frente Amplio en Uruguay en 2004, o el robusto resultado obtenido por el Partido de la Revolución Democrática en México y el Partido Acción Ciudadana en Costa Rica, que les llevó a ambos muy cerca del triunfo electoral en 2006. No sólo es necesario afirmar que la disponibilidad de recursos económicos es apenas una de las muchísimas variables que explican la dinámica electoral, sino que es preciso recordar uno de los hallazgos de múltiples investigaciones empíricas sobre las elecciones al Congreso en los Estados Unidos: el gasto electoral tiene rendimientos marginales decrecientes que, en algunos casos, pueden llegar a ser negativos. ${ }^{15}$

grados y con diversas modalidades. En contextos autoritarios y semi autoritarios el acceso ilimitado a esos recursos por quienes ostentan el poder es, con frecuencia, el rasgo definitorio del financiamiento político y el obstáculo fundamental para la existencia de una arena electoral equitativa. Los casos de Egipto o Rusia, entre muchos, vienen a la mente (véase Rabie, Amr Hashem, "Financing Egyptian Political Parties", ponencia presentada en la Conferencia sobre Integridad Política organizada por el Al Ahram Center for Political and Strategic Studies; Cairo, Egipto, 12-13 de enero de 2008.; Ammar, Dina, "Public Funding of Political Parties: The Case of Egypt", Documento preparado para la Conferencia sobre Integridad Política organizada por el Al Ahram Center for Political and Strategic Studies; Cairo, Egipto, 12 y 13 de enero de 2008; "Russian election lacked 'freedom, monitor says", The Washington Post, 4 de marzo de 2008). En todos los países, hay obvias y considerables dificultades para investigar este fenómeno. Eso no lo hace menos real, por supuesto. Sobre el caso venezolano véase: Unión Europea, Misión de Observación Electoral de la Unión Europea, Informe Final Elecciones Parlamentarias-Venezuela 2005, p. 45, http://www.sumate.org/Elecciones/2005Parlamentarias/2005_informe_final_ Union_Europea.pdf; Misión de Observación Electoral de la Unión Europea, Informe Final Elección Presidencial-Venezuela 2006, p. 41, http://www.sumate.org/Elecciones/20 06Presidenciales/2006_informe_final_Union_Europea.pdf; "Exigen ley que regule uso de recursos públicos en campaña”, El Universal, Caracas, 21 de febrero de 2009. En el caso de México, el uso de algunos programas sociales por parte del gobierno y las actuaciones del presidente Vicente Fox durante la campaña de 2006 fueron muy controversiales. Véase Tribunal Electoral del Poder Judicial de la Federación [TEPJF], Dictamen relativo al cómputo final de la elección de presidente de los Estados Unidos Mexicanos, declaración de validez de la elección y de presidente electo; Resolución del 5 de septiembre de 2006, México,, pp. 158-217, http://www.trife.gob.mx/documentacion/publicaciones/Infor mes/DICTAMEN.pdf; Córdova, Lorenzo, "La reforma electoral de 2007-2008: Reporte ejecutivo", documento inédito, 2008, p. 6; Valdéz Zepeda, Andrés, "México en su encrucijada: un análisis de la elección presidencial del 2006”, Contratexto digital, Universidad de Lima, Perú, año 4, núm. 5, 2006.

15 Sobre los rendimientos marginales decrecientes del gasto electoral, véase Welch, W. P., "The Effectiveness of Expenditures in State Legislative Races", American Politi- 
Asimismo, debe notarse que el tema de la distribución de recursos económicos es distinto al del costo de las campañas electorales, con el que frecuentemente se le asocia. El alto costo de las campañas puede sin duda suponer una importante barrera de acceso a la competencia electoral. Sin embargo, es necesario tratar este punto con cautela. No sólo la común afirmación de que el costo de las campañas electorales es prohibitivo en la región y está aumentando sin cesar es contenciosa desde el punto de vista empírico, ${ }^{16}$ sino que no necesariamente implica un desvalor para la democracia. En algunos casos puede simplemente denotar elecciones más competitivas, en las que más contendientes tienen acceso a recursos económicos suficientes para competir efectivamente. Este punto puede ser decisivo en algunos contextos. La experiencia de México, en donde la reforma electoral de 1996 favoreció el acceso de los partidos de oposición a un subsidio estatal excepcionalmente generoso, es un recordatorio de que una distribución más equitativa de los recursos electorales puede tener efectos considerables en la calidad de la competencia democrática, como lo ha advertido Giovanni Sartori. ${ }^{17}$ La experiencia mexicana sugiere algo más: en un contexto en el que los partidos de oposición deben competir con un partido fuertemente consolidado en todas las estructuras de poder, la alternabilidad puede depender precisamente de la capacidad de la oposición para gastar mucho dinero. El costo creciente de las elecciones no es, por sí mismo, un signo de patología democrática. La mala distribución de recursos económicos entre competidores electorales, en cambio, casi siempre lo es.

cal Quarterly, vol. 4, julio de 1976, y Jacobson, Gary, "Money and Votes Reconsidered: Congressional Elections, 1972-1982”, Public Choice, vol. 47, núm. 1, 1985. El ejemplo de Perú en 1990 es muy elocuente en este sentido. En un contexto de aguda crisis nacional y con un sistema de partidos virtualmente colapsado, cada dólar adicional erogado por la campaña de Vargas Llosa sirvió para implantar en el electorado la imagen de que su candidato era más de lo mismo, exactamente el mensaje propalado por la campaña "insurgente" de Fujimori. Sobre esta campaña véase Vargas Llosa, Mario, El pez en el agua, Madrid, Alfaguara, 2005.

16 Véase Casas Zamora, Paying for Democracy..., cit., pp. 111-117 y 159-162. Para otros contextos véase Pinto-Duschinsky, Michael, "Financing Politics: A Global View", Journal of Democracy, vol. 13, núm. 4, octubre de 2002, y Ansolabehere, Stephen et al., "Corruption and the Growth of Campaign Spending", en Lubenow, Gerald C. (ed.), A User's Guide to Campaign Finance Reform, Oxford, Rowman \& Littlefield Publishers, 2001.

${ }_{17}$ Woldenberg, José et al., "El modelo de financiación de los partidos políticos en México", en Castillo, Pilar del y Zovatto, Daniel (eds.), La financiación de la política en Iberoamérica, San José, IIDH-CAPEL, 1998; Sartori, Giovanni, Partidos y sistemas de partidos, Madrid, Alianza Editorial, 1991, p. 260. 


\section{La desarticulación de los partidos y del sistema de partidos}

Una democracia funcional requiere un sistema de partidos estable, no demasiado fragmentado y caracterizado por dinámicas centrípetas y no centrífugas. Asimismo, requiere de partidos sólidos, capaces de alimentar el proceso político continuamente y de ser algo más que maquinarias electorales. Ambos requerimientos, sobre todo el primero, son de particular importancia en los regímenes presidenciales prevalecientes en la región, que muestran una propensión importante a experimentar conflictos entre poderes cuando coexisten con sistemas de partidos altamente fragmentados. ${ }^{18}$

Si bien el financiamiento político no determina la volatilidad, el formato o la polarización del sistema de partidos, su regulación sí es capaz de crear incentivos que marginalmente afectan su comportamiento. De manera más directa, las reglas de financiamiento - y en particular el método de desembolso escogido para los subsidios estatales, donde éstos existen- pueden incidir decisivamente en la institucionalización de los partidos y en su consolidación como agrupaciones con vida permanente.

En ambas dimensiones las tendencias mostradas por la región no son favorables. Una revisión de la dinámica del sistema de partidos en 17 países latinoamericanos desde finales de la década de 1980 muestra un aumento del número efectivo de partidos en 10 de los 17 países. ${ }^{19}$ Por otro lado, la volatilidad electoral de la región continúa siendo comparativamente muy alta y alcanza niveles asombrosamente elevados en países como Perú y Guatemala, con sistemas de partidos con altísimos niveles de fragilidad. ${ }^{20}$ Por otro lado, con la posible excepción de los partidos mexicanos y de algunos ejemplos aislados en otros países (por ejemplo: Frente Amplio en Uruguay, Alianza Republicana Nacionalista en El Salvador, Partido Revolucionario Demo-

${ }_{18}$ Véase al respecto el análisis sobre los sistemas de partidos de América Latina, en Payne, Mark et al., La política importa. Democracia y desarrollo en América Latina, Washington D. C., BID-IDEA, 2006, pp. 165-196.

${ }_{19}$ Cálculo de los autores con base en cifras oficiales y metodología de Laakso, Marku y Taagepera, Rein, "Effective Number of Parties: A Measure with Application to Western Europe”, Comparative Political Studies, vol. 12, núm. 1, abril de 1979.

20 Madrid, Raúl, "Ethnic Cleavages and Electoral Volatility in Latin America and the Caribbean", Comparative Politics, vol. 38, octubre de 2005, p. 6. Véanse también datos en Payne, Mark et al., La política importa..., cit., pp. 183. 
crático en Panamá), los niveles de institucionalización de los partidos políticos en la región son sumamente bajos, aun en democracias muy consolidadas como Costa Rica, Uruguay o Chile. ${ }^{21}$

Los casos colombiano y mexicano merecen una mención especial. En el primero de ellos es muy posible que las reglas bastante liberales de acceso al financiamiento estatal — que le permiten beneficiarse incluso a candidatos propuestos por "movimientos sociales" o por "grupos significativos de ciudadanos" - contribuyeron a la virtual licuefacción que sufrió el sistema de partidos colombianos en la década anterior, parcialmente revertida por la reforma electoral de 2003. ${ }^{22}$ La experiencia mexicana, por su parte, en la que un cuantioso subsidio estatal ha sido dispuesto para cubrir las actividades partidarias permanentes es sugerente del poderoso efecto que pueden tener las subvenciones no electorales en la consolidación institucional de los partidos. México, que sólo en esta década culminó su transición democrática, tiene hoy acaso los partidos más robustos de toda la región, con vocación de permanencia y capacidad competitiva en todos los niveles.

Es importante que las reglas de financiamiento político no creen barreras excesivas a la participación electoral; sin embargo, es tan importante por lo menos que tiendan a favorecer - así sea marginalmente- la consolidación de los partidos y una cierta estabilidad del sistema de partidos.

\section{La pérdida de credibilidad de la regulación del financiamiento político}

Una regulación deficiente del financiamiento político puede ser tan negativa como la ausencia completa de normas en esta materia. Ello

${ }^{21}$ Véase al respecto el estudio, ya con algunos años de más, de Mainwaring, Scott y Scully, Timothy, "Introduction: Party Systems in Latin America", en id. (eds.), Building Democratic Institutions: Party Systems in Latin America, Stanford, Stanford University Press, 1995. También Casas Zamora, Paying for Democracy..., cit., p. 14, n. 22.

${ }^{22}$ De la Calle, Humberto, "Financiación de los partidos políticos y las campañas electorales en Colombia”, en Castillo, Pilar del y Zovatto, Daniel (eds.), La financiación de la política en Iberoamérica, San José, IIDH-CAPEL, 1998, pp. 106-111. Sobre la reforma electoral de 2003 y sus efectos véase Rodríguez Raga, Juan Carlos y Botero, Felipe, "Ordenando el caos: elecciones legislativas y reforma electoral en Colombia", Revista de Ciencia Política, Pontificia Universidad Católica de Chile, vol. 26, núm. 1, 2006. 
porque todo esfuerzo regulatorio tiende a levantar las expectativas de que nuevas normas serán capaces, al menos, de moderar los peores abusos en esta materia. Las reformas fracasadas dejan un sedimento de desilusión y cinismo que se convierte en una barrera a nuevos intentos de regulación.

Desafortunadamente, la región es pródiga en ejemplos de reformas mal diseñadas o desprovistas de recursos para ser adecuadamente puestas en práctica. La introducción de reglas de transparencia en el financiamiento privado en Costa Rica en 1996 constituye un ejemplo elocuente de los efectos derivados de un marco normativo mal concebido. La carencia de un mandato explícito para que las autoridades electorales verifiquen la contabilidad de los partidos y las estructuras de campaña, así como la ausencia de responsabilidades claramente individualizadas por el incumplimiento de la normativa, han condenado a la legislación costarricense a tener una limitada capacidad para regular los abusos en el financiamiento político. Esto lo reveló con toda claridad la campaña presidencial de 2002, cundida de irregularidades que afectaron, en distinto grado, a todos los partidos mayoritarios costarricenses. ${ }^{23}$ Aún más claro es el caso de la reforma argentina de 2002, cuya ejecución —en un país de 40 millones de habitantes, con estructuras federales e intensa actividad electoral a todos los nivelesfue dejada en manos de un grupo de 24 jueces federales, insuficientes para hacer cumplir las detalladas disposiciones de la legislación. A partir del momento en que, a 10 días de las elecciones, el candidato victorioso en la elección presidencial de 2003 reportó públicamente que sus gastos electorales habían ascendido a la suma de \$1, la legislación vio seriamente comprometida su credibilidad. ${ }^{24}$

La experiencia mexicana, por el contrario, muestra cómo la legislación bien diseñada, acompañada del fortalecimiento de las instituciones controladoras, de muchos recursos y de férrea voluntad política

${ }^{23}$ Casas Zamora, "Regulando el financiamiento político en Costa Rica: algunas reflexiones prácticas”, en Prado, Mimi (ed.), Modernización del Estado costarricense, San José, Centro Internacional para el Desarrollo Humano-Fundación Konrad Adenauer, 2004 pp. 240-244.

${ }^{24}$ Ferreira Rubio, Delia, El control del financiamiento de los partidos en Argentina: ¿Qué cambió con la nueva ley?, Buenos Aires, Universidad del CEMA, Serie Documentos de Trabajo núm. 292, 2005, pp. 10 y 11. Véase también, de mismo autor, "Financiamiento de los partidos políticos en Argentina"; presentación realizada en el seminario "La legislación comparada sobre financiación de los partidos políticos", Montevideo, Uruguay, 27 y 28 de noviembre de 2007. 
para sancionar incumplimientos, puede conducir a una aplicación creíble de las provisiones legales, capaz de controlar algunos de los peores riesgos en materia de financiamiento político. ${ }^{25}$

Como se ve, de cada una de estas cinco modalidades de riesgo la región está más que avisada. Introducir legislación adecuada y efectiva para regular el papel del dinero en la actividad política en América Latina es, por ello, imperativo. Para acometer la tarea de regular es preciso tener claro, para empezar, el menú de instrumentos normativos con que se cuenta y las lecciones tentativas que arroja la experiencia internacional, abundante aunque poco estudiada sistemáticamente.

\section{III. ¿Qué hacer? \\ Instrumentos de regulación y experiencia comparada}

El papel del dinero en la actividad política democrática puede ser regulado mediante una amplia gama de instrumentos legales, cuya presencia y combinación dan forma al sistema de financiamiento político (SFP). El SFP es el conjunto de normas que regula el indispensable flujo de recursos económicos hacia el sistema político y desde este último. Es el marco normativo dentro del cual los partidos y los candidatos pueden actuar legalmente para obtener y gastar recursos económicos para sus actividades, y dentro del cual las personas físicas y jurídicas - tanto públicas como privadas - pueden financiar esas actividades. Asimismo, el SFP define los instrumentos legales para supervisar y respaldar coercitivamente la aplicación de ese marco normativo.

La diversidad de instrumentos disponibles para regular el financiamiento político y las numerosísimas combinaciones posibles plantean problemas para los reformadores, pero también para quienes estudian esta materia, toda vez que identificar nítidamente los efectos de cada uno de los instrumentos de regulación y elaborar prescripciones a partir de esos efectos es una ardua tarea.

Con todo, a estas alturas, tras más de un siglo de intentos de regular el financiamiento político en la democracia, no es poco lo que

25 Orozco, Jesús, "Financiamiento y fiscalización de los partidos políticos en México", en Fontaine, Arturo et al. (eds.), Reforma de los partidos políticos en Chile, Santiago, PNUD-CEP-Libertad y Desarrollo-CIEPLAN, 2008. 
sabemos. Vale la pena detenerse, pues, en el examen de la diversidad de instrumentos regulatorios y algunas de las principales lecciones arrojadas por su aplicación en diversos contextos, incluido el latinoamericano.

Contrariamente a la percepción habitual, los países de América Latina tienen una larga tradición de regulación del financiamiento político. En particular, han sido pioneros en la adopción de subsidios directos para partidos y candidatos, como lo atestiguan los casos de Uruguay (1928), Costa Rica (1956) y Argentina (1961). El retorno de la democracia a la región ha generado, predeciblemente, un creciente interés en esta materia, que se ha vertido en numerosos esfuerzos regulatorios. La región ha avanzado en la adopción de normas y, ayudado en parte por una prensa cada vez más incisiva, el tema del financiamiento político está definitivamente instalado en la discusión pública. Esto último es, en sí mismo, un progreso considerable. Sin embargo, como se ha visto más arriba, son abundantes y graves los riesgos que persisten para las democracias de la región, derivados de la inadecuada regulación de la materia y, en particular, de la pobre ejecución de los controles existentes. $^{26}$

\section{Instrumentos de regulación del financiamiento político ${ }^{27}$}

Los instrumentos legales para regular el financiamiento político pueden ser clasificados en cinco categorías:

${ }^{26}$ Amplios análisis comparados de las reglas de financiamiento político en América Latina pueden encontrarse en Castillo, Pilar del y Zovatto, Daniel (eds.), La financiación de la política en Iberoamérica, cit.; Carrillo, Manuel et al. , Dinero y contienda políticoelectoral: reto de la democracia, México, Fondo de Cultura Económica, 2003; Griner, Steven y Zovatto, Daniel (eds.), De las normas a las buenas prácticas: el desafío del financiamiento político en América Latina, cit.; Zovatto, Daniel, "Dinero y política en América Latina”, Foreign Affairs en español, México, ITAM, vol. 5, núm. 4, 2005, y Zovatto, Daniel, "El financiamiento electoral: subvenciones y gastos", en Nohlen, Dieter et al. (eds.), Tratado de derecho electoral comparado de América Latina, México, Fondo de Cultura Económica, 2007.

27 Esta sección contiene información desarrollada extensamente en Casas Zamora, Paying for Democracy..., cit., cap. 1. Esta fuente puede ser consultada si se desea ver una descripción mucho más detallada de los SFP y los sistemas de financiamiento estatal en cerca de 50 democracias. Si bien los autores han tenido el cuidado de consultar y actualizar la información sobre las regulaciones del financiamiento político mencionadas en el texto, algunas inexactitudes menores pueden existir en algunos casos. 


\section{A. Regulaciones sobre las fuentes de financiamiento}

Esta categoría incluye aquellos instrumentos que regulan el flujo de recursos económicos hacia las actividades políticas, tanto controlando o prohibiendo el uso de ciertas fuentes de financiamiento (regulaciones "negativas" o "pasivas"), o bien estimulando el uso de otras fuentes (regulaciones "positivas" o "activas").

Los controles más extendidos pesan, como es de esperar, sobre las donaciones políticas privadas. Casi todas las democracias restringen el uso de, al menos, algunos tipos de donaciones privadas, aunque con niveles de intensidad muy dispares. Mientras algunos países (Grecia, por ejemplo) simplemente imponen un límite a los montos de las contribuciones, en la mayoría de los casos las democracias modernas prohíben absolutamente el uso de algunas fuentes de financiamiento. Los límites a las contribuciones individuales oscilan entre US\$350 por elección en Israel y los más de US\$250 000 por año en Japón. Las prohibiciones, por su parte, caen generalmente sobre las donaciones foráneas - prohibidas en más de 30 países-y sobre ciertos tipos de donaciones corporativas, típicamente aquellas de empresas estatales o de firmas beneficiarias de contratos o licencias otorgadas por el Estado.

La situación normativa en América Latina es consistente con esa descripción. Prácticamente todos los países latinoamericanos han introducido prohibiciones en el uso de ciertas fuentes de financiamiento y una amplia mayoría ha impuesto límites en relación con los montos de las contribuciones. A la fecha, sólo El Salvador no establece limitación alguna en esta materia. Entre las prohibiciones, las más comúnmente adoptadas son aquellas que pesan sobre las donaciones de gobiernos, instituciones o individuos extranjeros (la mayoría de los países, excepto El Salvador y Nicaragua), de contratistas del Estado (por ejemplo Argentina o Bolivia) y de fuentes anónimas (más de la mitad de los países; por ejemplo Costa Rica, Honduras, México). Igualmente importante es que algunos países de la región (Argentina, Honduras, México, Paraguay y Costa Rica, entre otros) han prohibido las donaciones de personas jurídicas. Por su parte, limitaciones diversas en cuanto al monto de las contribuciones individuales han sido introducidas en los casos de Argentina, Bolivia, Brasil, Colombia, Chile, Ecuador, Guatemala, México, Paraguay, Perú y Uruguay.

Tales restricciones sobre las fuentes privadas de financiamiento buscan responder a los primeros dos riesgos descritos más arriba, esto 
es, intentan minimizar las oportunidades de compra de influencia por parte de donadores poderosos o controversiales. Como sucede con otras medidas regulatorias de tipo restrictivo, los límites a las contribuciones suponen significativos problemas de aplicación, demandando, como mínimo, la presencia de un extendido sistema de reporte y auditoría de los recursos utilizados por los partidos y los candidatos, un requisito que ha probado ser difícil de satisfacer aun para las democracias más desarrolladas. ${ }^{28}$

Asimismo, los límites a las contribuciones, particularmente cuando son excesivamente bajos, pueden conducir a resultados perversos. Así, medidas draconianas para prohibir completamente las contribuciones privadas, como las empleadas en Francia antes de 1988 y la India en el periodo 1969-85, terminaron por incentivar prácticas de financiamiento singularmente opacas. ${ }^{29}$ Por ello, no es sorprendente que muchas democracias, particularmente en Europa Occidental, sean reacias a establecer comprensivos controles sobre las contribuciones, optando en cambio por restringir el peso financiero de los donantes privados por otros medios, como generosos sistemas de financiamiento público, cortas campañas electorales y restricciones severas sobre la publicidad electoral.

\section{B. Financiamiento estatal}

El SFP puede no sólo restringir el flujo de dinero hacia la política, sino que también puede intervenir activamente para darle forma. Puede hacerlo mediante la provisión de dinero, bienes o servicios públicos a los candidatos y los partidos. De hecho, el uso de subsidios estatales es, por mucho, la característica más común los SFP contemporáneos.

28 Sobre los obstáculos enfrentados por la Comisión Federal Electoral de los Estados Unidos (FEC) para aplicar los topes de contribución introducidos por el Federal Election Commission Act de 1974, véase Gross, Kenneth A., "The Enforcement of Campaign Finance Rules: A System in Search of Reform”, en Corrado, Anthony et al. (eds.), Campaign Finance Reform: A Sourcebook, Washington D. C., Bookings Institution Press, 1997; Federal Election Commission, Annual Report 1997, Washington D. C., Federal Election Commission, 1998, pp. 31-34; Sorauf, Frank J., Inside Campaign Finance: Myths and Realities, New Haven, Yale University Press, 1992, p. 185.

${ }^{29}$ Levush, Ruth et al., Campaign Financing of National Elections in Foreign Countries, Washington D. C., Law Library of Congress, 1991, pp. 90-92; Avril, Pierre, "Regulation of Political Finance in France", en Herbert, Alexander y Rei Shiratori, Rei (eds.), Comparative Political Finance among the Democracies, Boulder, Westview Press, 1994, pp. 85-89. 
El término "financiamiento estatal" comprende tres categorías básicas de subvención: subsidios directos (fondos públicos desembolsados a partidos y candidatos de acuerdo con un procedimiento definido por la ley); subsidios indirectos (subvenciones en especie, como el acceso a los medios de comunicación estatales), o subsidios específicos (fondos entregados a organizaciones relacionadas con los partidos o controladas por ellos, tales como las fracciones legislativas o sus institutos de investigación).

De estas categorías, la de los subsidios directos es, sin duda, la más relevante. De hecho, la adopción de subvenciones directas configura, probablemente, la tendencia más importante en materia de financiamiento político. Desde su temprana adopción en Uruguay en 1928 y durante las últimas cuatro décadas en particular, los subsidios directos han sido introducidos en más de 50 países. En América Latina, con el establecimiento en 2003 del financiamiento público directo en las legislaciones peruana y chilena, se consolidó una tendencia mayoritaria en la región a instaurar sistemas de financiamiento estatal directo. Hoy, las únicas excepciones a este fenómeno son Venezuela y, desde el año pasado, Bolivia, que eliminó los subsidios estatales directos incorporados en su legislación en 1997.

No obstante su generalizada adopción, la introducción de los subsidios estatales - en particular en su modalidad directa- no ha estado desprovista de polémica. Ello no sólo por el costo impuesto a los contribuyentes - que garantiza que, en casi todos los casos, la entrega de subsidios a los partidos y candidatos sea sumamente impopular- ${ }^{30}$ sino también por la incertidumbre sobre sus efectos. Los proponentes del financiamiento estatal enfatizan rutinariamente su importancia para disminuir la dependencia de los actores políticos respecto de los grandes donantes privados, crear condiciones económicas equitativas para las diferentes opciones políticas y fortalecer la institucionalización de las organizaciones partidarias. Correlativamente, sus detractores han sostenido por mucho tiempo su ineficacia como instrumento para proteger a los actores políticos de la compra de influencia, su tendencia a favorecer a los partidos establecidos y su inclinación a crear

${ }^{30}$ Independientemente de su configuración, los sistemas de financiamiento estatal son muy impopulares en todo el mundo, excepto quizá en los Estados Unidos, lo que resulta más bien sorprendente. Una revisión de este tema, con datos de encuestas en varios países europeos, particularmente Polonia, puede verse en Walecki, Marcin, Money and Politics in Poland, Warsaw, Institute of Public Affairs, 2005, pp. 253-259. 
situaciones de dependencia financiera de los partidos respecto del Estado, liberándolos de la necesidad de atraer nuevos miembros. Es un debate que dista de estar concluido, entre otras razones porque el financiamiento público - en particular los subsidios directos- constituye un instrumento extraordinariamente heterogéneo, que se resiste a las generalizaciones fáciles de sus efectos. ${ }^{31}$

En efecto, las configuraciones posibles de los sistemas de subsidio público son múltiples. Todo sistema de subvención directa debe definir cuatro puntos centrales:

- ¿Cuáles actores políticos recibirán el subsidio?

- ¿Con qué periodicidad serán desembolsados los fondos?

- ¿Cuáles barreras de acceso y reglas de asignación serán adoptadas?

- ¿Quién define el monto de la subvención y cómo?

Sobre el primer punto, la estructura central de los partidos políticos es la receptora por excelencia de los subsidios directos en la gran mayoría de los países. Sólo unos pocos países (por ejemplo Bélgica, Taiwán y Estados Unidos) no entregan subsidios a los organismos centrales de los partidos. En otros casos (por ejemplo Australia, Canadá, Austria y Suecia) los órganos subnacionales de los partidos son directamente subsidiados, en algunos casos con excepcional generosidad. ${ }^{32} \mathrm{El}$ apoyo directo del Estado a los candidatos presidenciales es mucho menos común, aunque se da en casos como Francia, Uruguay y Estados Unidos. Este último país es el único en el que el subsidio estatal cubre los procesos de nominación de candidatos presidenciales, un punto a tener en cuenta dada la creciente adopción del mecanismo de eleccio-

31 Véase Casas Zamora, Paying for Democracy..., cit., cap. 1.

32 Este es el caso, particularmente, de Austria y Suecia. Véase Müller, Wolfgang, "The Development of Austrian Party Organizations in the Post-War Period", en Katz, Richard S. y Mair, Peter (eds.), How Parties Organize: Change and Adaptation in Party Organizations in Western Democracies, Londres, Sage, 1994, pp. 54 y 55; Nassmacher, KarlHeinz, "Political finance in West Central Europe: Austria, Germany, Switzerland", en, Nassmacher, Karl-Heinz, Foundations for Democracy: Approaches to Comparative Political Finance, Baden-Baden, Nomos, 2001, p. 103; Klee, Gudrun, "Financing Parties and Elections in Small European Democracies: Austria and Sweden", en Gunlicks, Arthur (ed.), Campaign and Party Finance in North America and Western Europe, Boulder, Westview Press, 1993, pp. 183-189; Gidlund, Gullan y Koole, Ruud, "Political Finance in North of Europe: the Netherlands and Sweden”, en Nassmacher, Karl-Heinz, Foundations..., cit., p. 123. 
nes primarias abiertas en muchos países, particularmente en América Latina.

De acuerdo con su periodicidad, los subsidios directos pueden ser permanentes o electorales, siendo aquellos casi siempre desembolsados a los partidos en forma anual, con el propósito de apoyar diversas actividades no electorales, en particular la expansión y mantenimiento de la estructura partidaria. En muchos casos coexisten ambos tipos de subvención.

La distribución de estas opciones muestra patrones dignos de mención. Mientras casi todas las democracias de Europa Occidental proveen financiamiento permanente a los partidos, en las democracias de América del Norte y América Latina el financiamiento electoral sigue siendo prevaleciente. Ello refleja una distinta forma de entender la naturaleza y las funciones de los partidos. En Estados Unidos, por ejemplo, las reglas de subsidio reflejan la noción de que los partidos existen, en lo fundamental, para pelear batallas electorales y que son, en todo caso, menos importantes que los candidatos individuales. ${ }^{33}$ En Europa, por su parte, se ha adoptado una noción más comprensiva del papel de los partidos, como organizaciones permanentes esenciales para la tarea de gobernar. Esta distinción no es ajena a la división entre regímenes presidenciales en casi todo el Hemisferio Occidental y regímenes parlamentarios en Europa Occidental.

Debe decirse, sin embargo, que América Latina muestra una creciente aceptación del financiamiento público permanente para el fortalecimiento y desarrollo institucional de los partidos, incluyendo actividades tales como la investigación, la formación y la capacitación de cuadros partidarios. Tal es el caso de Argentina, Brasil, Colombia, Costa Rica, México, Panamá y Perú, entre otros.

El momento de desembolso de los subsidios electorales también presenta variaciones importantes. Esta característica puede tener una relevancia considerable, toda vez que las subvenciones exclusivamente poselectorales pueden implicar un obstáculo infranqueable para los partidos de reciente creación, con menores recursos financieros o con menor capacidad crediticia. En algunos países la subvención estatal opera como un reembolso post electoral de gastos (por ejemplo Aus-

${ }^{33}$ Katz, Richard S. y Kolodny, Robin, "Party Organization as an Empty Vessel: Parties in American Politics”, en Katz, Richard S. y Mair, Peter (eds.), How Parties Organize: Change and Adaptation in Party Organizations in Western Democracies, Londres, Sage, 1994. 
tralia), mientras en otros se permite el pleno acceso al subsidio antes de la elección (por ejemplo los Estados Unidos). En algunos países, como España, ambas opciones están mezcladas en diferentes grados.

En América Latina no existe un patrón homogéneo en cuanto al desembolso del financiamiento electoral. Unos pocos casos contemplan únicamente pagos post electorales (Nicaragua y Paraguay). En un caso (Argentina) se entregan los recursos exclusivamente antes de las elecciones. El resto de los países ha adoptado una combinación de desembolsos anteriores y posteriores a los comicios.

Casi todos los países que otorgan subvenciones directas han introducido algún tipo de barrera de acceso, con el fin de desincentivar la proliferación de candidatos y partidos. Con frecuencia, la barrera de acceso es definida por el logro de representación parlamentaria en la elección previa (por ejemplo Finlandia), pero puede también consistir en un número absoluto de votos (por ejemplo Dinamarca o Portugal), un cierto porcentaje de los votos (por ejemplo Alemania o Nicaragua), o una combinación de escaños y votos (por ejemplo Suecia o Costa Rica). Otros países han introducido múltiples umbrales para diferentes tipos de subsidio (por ejemplo Austria o Colombia). La ausencia total de barreras es menos común y normalmente está limitada a algunos subsidios específicos.

En América Latina, una amplia mayoría de los países que tienen sistemas de subvención estatal (con las excepciones de Chile y El Salvador) han previsto algún tipo de barrera legal para tener acceso al financiamiento público. Esas barreras oscilan desde niveles sumamente bajos, como en Honduras (10000 votos), hasta relativamente altos, como Brasil, donde se requiere haber obtenido un $5 \%$ de los votos en las últimas elecciones de la Cámara de Diputados.

Una vez definido el universo de receptores del subsidio directo, se aplican las reglas de asignación. La mayoría de los países asignan el grueso de los subsidios directos proporcionalmente, de acuerdo con el porcentaje de votos o escaños obtenido en la elección previa (por ejemplo Bélgica, Grecia y, en América Latina, Chile, El Salvador, Guatemala, Honduras, Uruguay [votos]; Finlandia, Suecia, Nicaragua o Paraguay [votos y escaños]). Sin embargo, muchos otros sistemas han optado por modificar la asignación proporcional de los fondos con algunas reglas que tienden a la igualdad absoluta entre los receptores, típicamente el desembolso de una parte del subsidio en partes iguales para todos los beneficiarios. Ese es el caso de Israel y de un número 
sorprendentemente elevado de países en América Latina (Argentina, Brasil, Colombia, Ecuador, México, Panamá, Perú, República Dominicana y Costa Rica [sólo la porción que se desembolsa antes de la elección]). En otros casos, como el canadiense o el francés, se ha establecido una suma fija de reembolso de gastos electorales, que separa la distribución del subsidio de los resultados en las urnas. Otros países, como Alemania y Estados Unidos, han sustituido la asignación proporcional o cuasi proporcional de subsidios por otros interesantes mecanismos (matching grants) como el desembolso de los fondos estatales de acuerdo con la capacidad de los partidos (Alemania) o los candidatos presidenciales (Estados Unidos) para atraer pequeñas contribuciones privadas. ${ }^{34}$

Sobre el procedimiento de definición del monto, cabe decir que en cada país que se ha introducido el financiamiento estatal directo, la definición del monto inicial del subsidio recae en las manos de los legisladores. A partir de ahí la mayoría de los países ha preferido formalizar en la ley las reglas de cálculo del subsidio para evitar su manipulación política o su aumento desmesurado. Algunos países hacen esto fijando una suma que ha de pagarse por cada escaño o voto (por ejemplo en Italia u Honduras), o simplemente encargando a un ente apolítico la definición del monto de la subvención (por ejemplo en México o Israel). En el caso de Israel esta opción se tomó luego de una larga lista de aumentos de los subsidios dispuestos por los mismos beneficiarios de la subvención. ${ }^{35}$

Si los métodos para definir los montos de subsidio estatal son heterogéneos, aún más diversas son las sumas que los países efectivamente asignan a la subvención estatal. Este punto es relevante, toda vez que resulta claro que cualquiera que sea el efecto buscado por la

${ }^{34}$ En Alemania, cada partido recibe un subsidio del 38\% del monto que logre recaudar en cuotas de membresía y donaciones individuales de menos de $€ 3300$. En el proceso de elecciones primarias, los candidatos presidenciales en Estados Unidos pueden optar por fondos estatales que "cazan" los primeros US\$250 de cada contribución privada recaudada.

${ }^{35}$ Hofnung, Menachem, “The public purse and the private campaign: political finance in Israel", Journal of Law and Society, vol. 23, núm. 1, marzo de 1996, p. 138; Mendilow, Jonathan, "Public Party Funding and Party Transformation in Multiparty Systems", Comparative Political Studies, vol. 25, núm. 1, abril de 1992, p. 109; Blechinger, Verena y Nassmacher, Karl-Heinz, "Political finance in non-Western democracies: Japan and Israel”, en Nassmacher, Karl-Heinz, Foundations for Democracy: Approaches to Comparative Political Finance, Baden-Baden, Nomos, 2001, pp. 168, 177 y 178. 
introducción de los subsidios directos, se requiere, como mínimo, que los montos del apoyo estatal sean relevantes con relación a los costos de la actividad política. Si los subsidios públicos han de tener algún resultado visible, deben alcanzar una cierta "masa crítica", en ausencia de la cual el financiamiento estatal simplemente deviene un instrumento inocuo. Los casos latinoamericanos oscilan entre los montos más bien generosos de subsidio — de los que México es el caso más conspicuo- hasta sumas como las que en algún momento mostraron Ecuador y Guatemala, cuya capacidad para generar impactos políticos es más que dudosa.

Tabla 1

Subsidios estatales directos por año y votante registrado en 25 democracias (circa 1990's)

\begin{tabular}{|c|c|c|}
\hline País & US\$ & $A \tilde{n} o s^{*}$ \\
\hline Austria & 16.5 & $1995-1998$ \\
\hline Francia & 14.9 & 1995-1996 \\
\hline Suecia & 12.1 & 1999 \\
\hline Israel & 11.2 & 1996-1998 \\
\hline México & 3.3 & $1997-1999$ \\
\hline República Dominicana & 3.2 & 2000 \\
\hline Japón & 2.8 & 1995-1999 \\
\hline Alemania & 2.0 & 1995-1998 \\
\hline Australia & 1.9 & 1996-1998 \\
\hline Panamá & 1.8 & 1999-2004 \\
\hline Uruguay & 1.7 & 1999-2004 \\
\hline Costa Rica & 1.6 & $2002-2006$ \\
\hline España & 1.6 & $1998-2000$ \\
\hline Italia & 1.4 & 1999-2001 \\
\hline Nicaragua & 1.2 & 2001-2006 \\
\hline Portugal & 1.0 & 1995-1996 \\
\hline Bolivia & 0.6 & $1997-2002$ \\
\hline El Salvador & 0.5 & 1999-2004 \\
\hline Holanda & 0.4 & 1999 \\
\hline Honduras & 0.2 & 2001-2005 \\
\hline Estados Unidos & 0.2 & $1992-1996$ \\
\hline Canadá & 0.2 & 1993-1997 \\
\hline Dinamarca & 0.2 & $1988-1990$ \\
\hline Ecuador & 0.2 & 1995-1997 \\
\hline Guatemala & 0.02 & 1999-2003 \\
\hline
\end{tabular}

* Incluye un año electoral para todos los países, excepto Suecia y Holanda. En estos casos, sin embargo, los partidos no reciben subsidios adicionales durante el año electoral. Fuentes: Casas Zamora (2003) y (2005). 
Para finalizar la revisión de los mecanismos de financiamiento estatal, es preciso decir una palabra sobre los subsidios indirectos y específicos, que generalmente complementan en forma más modesta a las subvenciones directas. Aparte de la práctica casi universal de otorgar apoyo institucional a los miembros del Poder Legislativo — práctica que sólo parcialmente puede ser considerada un apoyo a los partidos políticos strictu sensu - otras tres formas de subsidio indirecto merecen ser mencionadas: el uso privilegiado o gratuito de los servicios públicos; las exenciones impositivas para las donaciones políticas, y la emisión gratuita de publicidad en los medios de comunicación estatales. El uso gratuito del correo para efectos de contactar a los votantes es muy común a nivel internacional (por ejemplo Austria, Finlandia, Francia, Italia, Japón y Reino Unido). En muchos otros casos, como Canadá, Francia, Alemania, Holanda, Taiwán, Chile y México, por mencionar algunos, exenciones fiscales han sido dispuestas para incentivar las donaciones políticas y su transparencia, en algunos casos específicamente dirigidas a la recaudación de pequeñas contribuciones (como en Canadá y Alemania). Finalmente, el acceso gratuito a los medios de comunicación estatales es una práctica muy extendida en Europa Occidental y, crecientemente, en otras regiones. Esto es un reconocimiento explícito a la enorme importancia de los medios de comunicación social —en particular la televisión - que hoy constituyen la arena fundamental de las luchas electorales.

Este último punto merece particular atención en América Latina. En efecto, la modalidad de subsidio indirecto más importante en la región lo constituye el acceso gratuito concedido a partidos y candidatos a los medios de comunicación estatales, privados o a ambos. Este beneficio se utiliza en buena parte de la región (con excepción de Venezuela [que carece de todo tipo de subvención pública], así como Costa Rica, Honduras y Nicaragua), casi siempre otorgando acceso gratuito a los medios estatales de comunicación, durante la vigencia de la campaña electoral. ${ }^{36}$ Únicamente en Brasil, Colombia, México, Panamá y Perú la legislación electoral especifica que el acceso de los partidos a los medios de comunicación es de carácter permanente. En algunos casos (Brasil, Chile, México y, desde 2010, Argentina), el

${ }^{36}$ Un análisis sobre el acceso de los partidos a los medios de comunicación en América Latina se encuentra en Griner, Steven y Zovatto, Daniel (eds.), De las normas a las buenas prácticas: el desafío del financiamiento político en América Latina, cit., pp. 314-319. 
acceso a una "franja" gratuita de publicidad en los medios coexiste con una prohibición de la adquisición de espacios adicionales de publicidad en la televisión o la radio. ${ }^{37}$ En los demás casos, sin embargo, la "franja" puesta a disposición por el Estado no impide la posibilidad de contratar espacios publicitarios privadamente.

En la medida en que los subsidios indirectos se pagan en especie, su valor es muy difícil de establecer en muchos países. Debe notarse, sin embargo, que en el contexto latinoamericano, al menos, la utilidad de los subsidios indirectos para los actores políticos tiende a ser más bien limitada. Los efectos de los beneficios impositivos para las donaciones están limitados por la baja efectividad de los sistemas de recaudación de impuestos en la región. Asimismo, el acceso a los medios de comunicación estatales, particularmente a la televisión, tiende a ser irrelevante en vista de la baja audiencia que tales medios generalmente tienen en América Latina.

¿Qué sabemos sobre los efectos del financiamiento estatal para partidos y candidatos? La respuesta a esta pregunta es extremadamente compleja, habida cuenta de la heterogeneidad de los mecanismos de subsidio y su imbricación con la estructura institucional que les rodea, que condiciona sus efectos. Pese a eso, la evidencia disponible tiende a mostrar tres cosas:

- Los subsidios estatales tienen un efecto bastante limitado en el control de las prácticas cuestionables de financiamiento político. Las experiencias de Canadá y casi toda Europa Occidental sugieren que los subsidios estatales pueden efectivamente reducir el peso de las grandes donaciones privadas en las finanzas

37 Brasil prohíbe en la televisión la propaganda electoral comercial, garantizándoles a cambio a los partidos una franja diaria de publicidad gratuita durante la campaña electoral. Chile, por su parte, prohíbe la contratación en televisión abierta, en donde otorga la franja gratuita, pero es posible contratar propaganda electoral en radioemisoras, televisión por cable y prensa escrita. En el caso de México, los partidos políticos pueden acceder a la radio y a la televisión sólo a través de los tiempos públicos (la suma de los tiempos del Estado y de los llamados tiempos fiscales). El Instituto Federal Electoral será la única autoridad facultada para administrar esos tiempos, y si considera que los mismos resultan insuficientes podrá tomar las medidas necesarias para su ampliación. En 2009, en Argentina, la Ley núm. 26571 incorporó nuevas modificaciones, siendo una de las reformas más trascendentes la prohibición de contratar espacios de publicidad privada en medios masivos de comunicación, debiendo utilizarse exclusivamente los espacios públicos otorgados. 
partidarias. Sin embargo, esto es el resultado de la presencia de una compleja combinación de factores institucionales (campañas cortas, restricciones a la emisión de publicidad electoral, incentivos fiscales para las donaciones pequeñas, etcétera), antes que de la simple disponibilidad y generosidad de los subsidios públicos. Aún más, la lista de países en los que la existencia de generosísimos sistemas de subvención ha sido totalmente incapaz de evitar graves irregularidades en el financiamiento político incluye a Israel, Francia, España, Italia, Austria y Alemania. ${ }^{38}$

- El financiamiento público puede tener y usualmente tiene un efecto equilibrador de la competencia electoral. No existe evidencia alguna de que, como lo sostienen algunos críticos, el financiamiento estatal tienda a osificar el sistema de partidos. Por el contrario, la información disponible sugiere que los sistemas de subsidio tienden a favorecer a los partidos pequeños y que, en algunos casos, son decisivos en las posibilidades de competir de partidos y candidatos sin vínculos cercanos con los sectores empresariales. En América Latina, en particular, el financiamiento estatal suele ser casi la única forma de equilibrar el desproporcionado peso de pequeños círculos empresariales en las finanzas partidarias. $^{39}$

- Cuando los subsidios se entregan a los partidos y en particular cuando los desembolsos se hacen anualmente, los fondos estatales pueden tener un efecto ostensible en el crecimiento y robustecimiento de las estructuras partidarias. Aunque este efecto "burocratizante" ha sido impugnado en algunos contextos desarrollados como un signo de debilitamiento del poder de los miembros sobre la dirigencia partidaria, en el caso de la mayoría de las democracias en América Latina, el fortalecimiento de las

38 Véase, entre muchos, "European Politics Plagued by Funding Scandals", The Guardian, 4 de diciembre de 1999; Blechinger y Nassmacher, op. cit., pp. 178-180; Galiardo, Juan Luis y Berbell, Carlos, FILESA: Las tramas del dinero negro en la política, Madrid, 1995; Rhodes, Martin, "Financing Party Politics in Italy: a Case of Systemic Corruption", West European Politics, vol. 20, núm. 1, enero de 1997; Pujas, Veronique y Rhodes, Martin, Party Finance and Political Scandal in Latin Europe, Florence, European University Institute, Robert Schuman Centre, 1998; Pulzer, Peter, "Votes and resources: Political finance in Germany", German Politics and Society, vol. 19, núm. 1, primavera de 2001, pp. 31 y 32.

39 Casas Zamora, "Financiamiento de campañas en Centroamérica y Panamá", Cuadernos de CAPEL, San José, núm. 48, 2003, y id., Paying for Democracy..., cit. 
estructuras partidarias es, más bien, una necesidad sistémica de la más alta importancia.

Debe insistirse en que estas son simplemente tendencias cuya aplicación en el caso concreto es enteramente contingente al diseño de cada sistema de subsidio, a su relevancia económica y a su relación con el sistema electoral y, en general, el marco institucional en el que ocurre la competencia democrática.

\section{Regulaciones sobre el gasto electoral}

Se incluyen aquí las reglas que establecen topes generales al gasto electoral de los partidos y candidatos, así como los límites y prohibiciones que pesan sobre algunos rubros específicos, particularmente la publicidad electoral. También se incluyen en esta categoría los límites dispuestos para la duración de las campañas.

Los topes generales de gasto son poco comunes entre las democracias. Esto es un reflejo de sus significativos problemas normativos y prácticos. La experiencia acumulada con los topes generales es entreverada en el mejor de los casos. Aun los casos más exitosos, como Gran Bretaña y Canadá, donde los límites han sido rigurosamente puestos en práctica y generalmente reconocidos como algo positivo, muestran algunos de los complejos dilemas inherentes a su aplicación. En Gran Bretaña, los topes de gasto por distrito electoral perdieron gradualmente su relevancia con el crecimiento secular del gasto realizado por los partidos a escala nacional, sólo recien controlado por la legislación. ${ }^{40}$ Entre tanto, en Canadá, la regulación de los gastos realizados por terceros ajenos al proceso electoral con el fin de incidir en su resultado, ha demostrado ser prácticamente imposible pese al visible papel que esos desembolsos han jugado en algunos comicios. ${ }^{41}$ En casi todos los otros casos los topes generales han sido ineficaces por distintos motivos que van desde la inadecuada definición de lo que

40 Un tope nacional de gastos operó por primera vez en la elección general de 2001.

${ }^{41}$ Ewing, Keith D., Money, Politics and Law: A Study of Electoral Campaign Finance Reform in Canada, Oxford, Clarendon Press, 1992, pp. 220-225; Stanbury, William T., "Financing Federal Politics in Canada in an era of Reform", en Gunlicks, Arthur (ed.), Campaign and Party Finance in North America and Western Europe, Boulder, Westview Press, 1993, pp. 97-99; Royal Commission on Electoral Reform and Party Financing, Reforming Electoral Democracy: volume 1, Canadá, Royal Commission on Electoral Reform and Party Financing, 1991, pp. 327-328. 
ha de contar como gasto electoral hasta la introducción de topes excesivamente bajos, pasando por la debilidad de los mecanismos de supervisión y la presencia de fuertes incentivos hacia el aumento del gasto derivados de otras características institucionales. Así, mientras por mucho tiempo los topes fueron demasiado altos para ser útiles en España, en otros países, como Australia, Colombia, India, Israel, Rusia, Corea del Sur, Ucrania y los Estados Unidos (1925-74), los actores políticos consistentemente los han ignorado. ${ }^{42}$

Con la intención de evitar algunas de estas consecuencias, otros SFP han enfocado sus restricciones hacia rubros singularmente visibles y onerosos, como la publicidad electoral. Casi todas las democracias en Europa Occidental prohíben la compra de publicidad electoral en la televisión, al tiempo que otorgan espacios publicitarios gratuitos a los partidos en los medios de comunicación estatales. Como hemos visto más arriba, esta opción ya ha sido adoptada, con variaciones, por algunos países latinoamericanos (Argentina, Brasil, Chile y México). ${ }^{43}$

Si bien esta solución ha sido generalmente reconocida como una forma eficiente de reducir los costos de la actividad electoral y reducir la presión económica sobre los partidos, la aplicabilidad general de este modelo es dudosa. Para funcionar requiere, entre otras cosas, de la presencia de poderosas empresas estatales de comunicación - algo poco común en las democracias fuera de Europa Occidental-, así como, probablemente, la existencia de una competencia electoral centrada en los partidos políticos, que evite la atomización de la publicidad que se presenta en los sistemas orientados a las candidaturas individuales. Quizá más importante es el hecho de que los efectos de este modelo en la protección de la equidad electoral son ambiguos. Como es el caso con los topes generales de gasto, los límites a la emisión de publicidad pueden convertirse en una injusta protección a los partidos oficiales y en un obstáculo importante para la oposición, particularmente en

${ }^{42}$ Pajares-Montolío, Emilio, La financiación de las elecciones, Madrid, Congreso de los Diputados, 1998, pp. 137-145; Levush, Ruth et al., Campaign Financing of National Elections in Foreign Countries, Washington D. C., Law Library of Congress, 1991, pp. 89, 126, 155; Park, Chan Wook, "Financing Political Parties in South Korea: 1988-1991", en Alexander, Herbert y Shiratori, Rei (eds.), Comparative Political Finance Among the Democracies, Boulder, Westview Press, 1994, pp. 181 y 182; Cepeda-Ulloa, Fernando, Financiación de campañas políticas, Bogotá, Ariel, 1997, pp. 94-97; Walecki, op. cit., p. 410.

${ }^{43}$ Ecuador, Nicaragua y, de forma indirecta, Costa Rica, han introducido, además, algunos límites a la impresión de publicidad electoral en la prensa escrita. 
aquellos casos en que los gobernantes continúan disfrutando de un acceso ilimitado a los medios de comunicación oficiales.

\section{Regulaciones tendientes a la transparencia financiera}

El cuarto grupo de reglas es aquel que obliga a los partidos, candidatos y otros actores políticos a reportar a las autoridades públicas las fuentes de sus recursos económicos y/o el uso dado a esos recursos. También incluye las reglas que definen si esa información es o no auditada $y$, finalmente, si es o no publicada.

Estas regulaciones presentan considerables variaciones entre países. Por lo general, imponen la obligación de elaborar reportes financieros a los partidos políticos más que a los candidatos, sobre actividades regulares tanto como electorales, con divulgación de las fuentes de financiamiento así como de los gastos, y con la realización de auditorías de la información por parte de alguna autoridad competente. En el caso de América Latina, con excepción de El Salvador, todos los países imponen la obligación a los partidos de reportar periódicamente sus finanzas, en tanto sólo unos pocos lo hacen, además, con los candidatos individuales (Brasil, Colombia, Chile, Panamá, Uruguay y Venezuela). Además, en todos los demás países existe algún órgano encargado del control y la fiscalización del financiamiento de los partidos, tarea que ha sido asignada en la mayoría de los casos a los organismos electorales. La experiencia mexicana es particularmente relevante en este sentido, en la medida en que el Instituto Federal Electoral tiene la potestad de obligar a los partidos a tener cuentas únicas, así como de realizar fiscalización in situ y aleatoria durante la temporada electoral, facultades que el organismo electoral ha utilizado extensivamente.

Por último, la situación en cuanto a la publicación de información es bastante menos clara en la región. Si bien varios países (entre ellos Argentina, Brasil, Colombia, Costa Rica, Ecuador, México, Nicaragua, Perú, Uruguay y, parcialmente, Panamá) obligan a divulgar los resultados de las auditorías realizadas sobre las cuentas de candidatos y partidos, en el resto de la región, esa información no necesariamente entra en el debate público.

Las reglas de transparencia buscan arrojar luz sobre las fuentes de apoyo de partidos y candidatos, así como sobre el cumplimiento por parte de estos de la legislación de financiamiento político. Revelar esa información puede tener un valor intrínseco para la democracia, pero las reglas de transparencia también tienen una decisiva importancia 
instrumental para hacer posible el éxito de otras medidas de regulación del financiamiento político, como los límites a las contribuciones $y$ al gasto. La eficacia de los topes depende casi enteramente de la presencia de un sólido sistema de reporte y divulgación de las finanzas de partidos y candidatos.

Estas reglas son la pieza maestra de la regulación del financiamiento político en muchos países, en particular los Estados Unidos. Con todo, su aplicación no está exenta de agudos dilemas normativos y prácticos. Por un lado, estas reglas implican la divulgación pública de información clave sobre la vida interna de las organizaciones políticas y, por ello, un cierto nivel de control estatal sobre ellas. Por otro lado, estas normas reflejan la noción de que, antes que asociaciones privadas, los partidos son entidades cuasi públicas y que los beneficios sociales de divulgar las fuentes de apoyo financiero de los actores políticos son más importantes que la protección de la privacidad de los donadores. ${ }^{44}$ Ambas nociones han sido consistentemente rechazadas en muchas democracias, incluso algunas fuertemente consolidadas, como Suecia y Suiza. La protección de la privacidad es una preocupación particularmente sensible en democracias que recientemente han abandonado un pasado autoritario, en las que el temor al acoso gubernamental está aún fresco en la mente de muchos actores políticos. ${ }^{45}$

\section{E. Régimen sancionatorio}

Esta categoría incluye todas las sanciones dispuestas para las eventuales violaciones a los límites, prohibiciones y obligaciones derivadas de las cuatro categorías normativas anteriores.

${ }^{44}$ La naturaleza cuasi pública de los partidos políticos ha sido discutida desde el momento en que fueron mencionados por la Constitución de Weimar en Alemania en 1919. Muchas Constituciones contemporáneas, especialmente en América Latina, explícitamente atribuyen a los partidos un papel crucial en el sistema democrático. La noción de que los partidos desempeñan funciones políticas vitales y proveen "bienes públicos de tipo político" ha sido frecuentemente usada para justificar la introducción de algunas medidas de supervisión sobre sus asuntos internos, incluso sobre la forma en que financian sus actividades. Véase García-Laguardia, Jorge Mario, "Constitucionalización de los partidos políticos”, Diccionario Electoral, San José, CAPEL-IIDH, 1989.

${ }_{45}$ Este tema se ha discutido, por ejemplo en Chile, Panamá y buena parte de Europa Central y del Este. Véase Valdés Prieto, Salvador et al., "Proposiciones sobre el financiamiento de la actividad política”, Estudios Políticos, núm. 78, otoño de 2000, pp. 420-437; La Prensa Panamá, 22 de julio de 1995; El Panamá América, 14 de agosto de 2001; Walecki, op. cit., pp. 413 y 414. 
A nivel internacional, las multas son, por mucho, la modalidad más común de sanción por la violación de la legislación de financiamiento político, y han sido utilizadas en algunos casos - México e Israel, en particular-con excepcional severidad. ${ }^{46}$ Con frecuencia, tales multas están ligadas a la provisión de subsidios estatales, que en muchos países se han convertido en una herramienta fundamental para asegurar el cumplimiento de otras regulaciones al financiamiento político. Así, la comisión de diversos tipos de irregularidades financieras por parte de los partidos - por ejemplo la presentación de reportes tardíos o incompletos - es sancionada con la retención de subvenciones estatales en Austria, Alemania, España y Portugal, entre otros países. En América Latina, en tanto prácticamente todos los países (con excepción de El Salvador, Guatemala ${ }^{47}$ y República Dominicana) han dispuesto multas para respaldar los controles al financiamiento político, la utilización de los subsidios estatales como mecanismo coercitivo es bastante menos extendida.

Aunque las penas privativas de libertad existen en muchos textos legales de regulación del financiamiento político, su imposición es más bien excepcional en esta materia y se limita, por lo general, a casos con una larga historia de escándalos en las finanzas partidarias.

${ }^{46}$ Luego de la elección de 2000 en México, el Partido Revolucionario Institucional, el Partido Acción Nacional y el Partido Verde Ecologista de México fueron sancionados con multas equivalentes a US $\$ 100$ millones, US $\$ 35$ millones y US $\$ 18$ millones, respectivamente, por serias irregularidades en el financiamiento de sus campañas. Véase Núñez, Arturo, "Análisis comparativo sobre financiamiento de campañas y partidos políticos en México", ponencia presentada en el Taller sobre Financiamiento Político organizado por la Organización de Estados Americanos e International IDEA, San José, Costa Rica, 8-9 de agosto de 2003, p. 11; Orozco, Jesús, "Financiamiento y fiscalización de los partidos políticos en México", en Fontaine, Arturo et al. (eds.), Reforma de los partidos políticos en Chile, Santiago, PNUD-CEP-Libertad y Desarrollo-CIEPLAN, 2008., p. 364. En enero de 2000, el Partido Laborista de Israel fue multado con US\$3.5 millones por recaudar donaciones ilegales. Multas en los cientos de miles de dólares son comunes en Israel. Véase Blechinger y Nassmacher, op. cit., p. 178; Hofnung, profesor del Departamento de Ciencia Política, Universidad Hebrea de Jerusalem, ex-miembro del Comité Directivo del Partido Meretz (Israel); entrevista, Ciudad de México, 7 de junio de 2001. El caso de Chile, por su parte, merece ser mencionado. En las últimas tres elecciones nacionales celebradas en ese país sudamericano, particularmente en los comicios municipales, se ha sancionado con multas a varios centenares de candidatos.

47 Vale aclarar, que en el caso de Guatemala, la última reforma a la ley realizada en 2004, contempla la aplicación de sanciones administrativas y penales, pero sin definición clara dentro del mismo marco legal. Esto ha limitado la aplicación de las sanciones por parte del órgano electoral. 
En Israel y Japón, por ejemplo, algunos políticos han sido efectivamente sancionados y encarcelados por la violación a las regulaciones del financiamiento de campañas. ${ }^{48}$

En materia sancionatoria, como en otras, la experiencia internacional es sugerente de la importancia de tener una dosis de precaución, "para no caer en el error de la sobrerregulación ni en la criminalización de la política". ${ }^{49}$ La imposición de sanciones excesivamente severas ha mostrado tener efectos ambiguos y, en algunos casos, hasta contraproducentes. Si aun las más pequeñas faltas acarrean serias penas, las autoridades encargadas de aplicarlas pueden mostrarse reacias a imponerlas. En países como Australia y Canadá, en los que la ley no deja más opción que la vía penal para sancionar violaciones a la legislación de financiamiento político, este camino ha sido sistemáticamente evitado y ha dado lugar a enfoques más dirigidos hacia la reparación de los daños derivados del incumplimiento de la ley. ${ }^{50} \mathrm{De}$ la misma manera, la aplicación de devastadoras sanciones electorales - como la anulación de la elección de los políticos que infringen la ley (por ejemplo en Francia y la India) o la cancelación inmediata del asiento de registro de los partidos que violan la legislación (por ejemplo en Senegal) - ha sido casi siempre evitada en razón de sus consecuencias políticas, potencialmente muy serias. ${ }^{51}$

48 Blechinger y Nassmacher, op. cit; Hofnung, op. cit.

49 Griner y Zovatto, op. cit., p. 325.

50 Amr, Dima y Lisowski, Rainer, "Political finance in Old Dominions: Australia and Canada”, en Nassmacher, Karl-Heinz, Foundations for Democracy: Approaches to Comparative Political Finance, Baden-Baden, Nomos, 2001; Gray, Bill, ex-Comisionado Electoral de Australia; entrevista, Ciudad de México, 6 de junio de 2001. Vale la pena mencionar aquí la experiencia de los Estados Unidos, donde la capacitación obligatoria de los responsables de campaña es utilizada con frecuencia como una medida alternativa a las multas por violaciones a las reglas de financiamiento. Para los casos de transgresiones al Federal Election Campaign Act, la Comisión Federal Electoral ha introducido un proceso de resolución alternativa de disputas (RAD) que, en sus propias palabras, "consiste en una serie de procedimientos constructivos y eficientes para resolver disputas mediante el mutuo consentimiento de las partes involucradas. La RAD incentive a las partes a establecer negociaciones que rápidamente conducen a la solución de la controversia”. Entre otras cosas, esto permite a los partidos y a las autoridades evitar los altos costos y la tensión que suele acompañar a los mecanismos tradicionales de aplicación de la ley. Véase Federal Election Commission, "Alternative Dispute Resolution Program", 2002, http://www.fec.gov/pages/brochures/adr.shtml\#What\%20is\%20ADR.

${ }_{51}$ Koole, Ruud, "Political finance in Western Europe: Britain and France", en Nassmacher, Karl-Heinz, Foundations for Democracy: Approaches to Comparative Political 
La experiencia latinoamericana es reveladora en este sentido. A pesar de que las sanciones penales para donantes o candidatos existen en la legislación electoral en nueve países del subcontinente, su aplicación ha sido prácticamente nula, con la posible excepción de México. ${ }^{52}$ Un estudio reciente de la experiencia de los países centroamericanos, donde no ha habido una sola condena penal o electoral por asuntos relacionados con el financiamiento de partidos - pese a numerosos casos de violación flagrante de la legislación de control- sólo sirve para confirmar este fenómeno. ${ }^{53}$

Griner y Zovatto han señalado que sin un sistema eficaz de sanciones que comprenda, no sólo las tradicionales multas, sino también castigos que afecten la libertad individual, las normas sobre financiamiento no pasarán de ser un conjunto de buenos propósitos. ${ }^{54}$ Sin embargo, la evidencia comparada sugiere que, más importante aún que la severidad de los castigos, es la existencia de un régimen gradual, variado y, sobre todo, creíble de sanciones. Su presencia añade gran potencia a las regulaciones sobre el financiamiento político.

\section{Sobre la heterogeneidad de los sistemas de financiamiento político}

Esta somera revisión de los instrumentos básicos de regulación del financiamiento político sugiere un punto crucial: no hay soluciones regulatorias obvias ni mucho menos únicas a los retos planteados por el papel del dinero en la política. Las curas milagrosas típicamente ofrecidas en las discusiones sobre la reforma al financiamiento políti-

Finance, Baden-Baden, Nomos, 2001, p. 89; Jain, Randhir, profesor del Departamento de Ciencias Políticas, Universidad de Dehli, India; entrevista, Ciudad de México, 6 de julio de 2001; Mbodj, El Hadj, profesor del Departamento de Derecho, Universidad Cheikh Anta Diop University, Senegal; entrevista, Ciudad de México, 8 de junio de 2001. Sin embargo, en Francia se han presentado algunos casos en los cuales han sido canceladas las credenciales de funcionarios electos debido a violaciones incurridas contra las leyes de financiamiento de campañas. Véase González-Varas, Santiago, La financiación de los partidos políticos, Madrid, Dykinson, 1995, pp. 171 y 172; Doublet, Yves-Marie, L'Argent et la Politique en France, París, Económica, 1997, pp. 48-50.

${ }_{52}$ Griner y Zovatto, op. cit., tabla 13, p. 367.

53 Véase Casas Zamora, "Financiamiento de campañas en Centroamérica y Panamá", Cuadernos de CAPEL, San José, núm. 48, 2003.

${ }^{54}$ Griner y Zovatto, op. cit., p. 325. 
co no son más que espejismos. En esta materia la regulación implica complejas escogencias normativas y prácticas, cuyo éxito está lejos de estar garantizado. Las respuestas a los urgentes problemas planteados en la sección anterior están cundidas de elementos valorativos que restringen el rango de soluciones aceptables en un contexto político determinado. Así, la decisión de proteger más o menos la privacidad de los ciudadanos al hacer donaciones políticas, o de intervenir más o menos en el ámbito interno de los partidos políticos, o de privilegiar más o menos la libertad de expresión frente a la igualdad electoral, evidentemente cambiará la prioridad otorgada a diferentes temas y, en última instancia, el talante de la reforma adoptada.

Cada sistema político combina los instrumentos de regulación del financiamiento político en forma muy diversa, de acuerdo con sus urgencias coyunturales, los rasgos de su cultura política, las características del entorno institucional preexistente $y$, como siempre, los intereses políticos de quienes elaboran las normas.

Nada de esto implica que la experiencia internacional sea irrelevante como guía o que quepa defender un relativismo normativo ramplón y peligroso, para el que todos los esquemas de regulación del financiamiento político valen lo mismo y ninguno vale nada. Lo único que esta advertencia impone es una cierta modestia en el alcance de las prescripciones que se hacen en esta materia. Sí es posible identificar algunos instrumentos regulatorios que han mostrado su utilidad para controlar razonablemente bien algunos de los principales riesgos derivados del financiamiento político y los autores lo haremos en la última sección de este documento. Pero es necesario tener claro que la adopción de esos instrumentos no es posible o aun deseable en todos los contextos y que sus efectos son siempre contingentes al entorno institucional preexistente. A este punto regresaremos más adelante.

\section{Lecciones sobre la reforma del financiamiento político}

Que una regulación adecuada y efectiva del financiamiento político sea muy necesaria en América Latina, no la hace inevitable. Como se ha visto en la segunda sección de este trabajo, la historia reciente de la región está llena de ejemplos de reformas condenadas al fracaso por 
problemas en su diseño y ejecución. En muchos casos tales defectos no son más que la materialización de intereses opuestos a la regulación de una materia muy sensible para la competencia electoral. En otros, sin embargo, los resultados decepcionantes no son más que el reflejo de la inflación retórica, los mitos y las expectativas desproporcionadas que casi siempre acaban gobernando la discusión del tema. Si bien es positiva y hasta necesaria, la creciente obsesión de la prensa con el financiamiento político en muchas democracias ha servido para propagar una poderosa mitología en la que traficantes de influencias, personajes corruptos, reformadores omniscientes y la subasta al por mayor de decisiones de política pública ocupan los lugares centrales. Frecuentemente estas imágenes tienen poco contacto con las realidades del financiamiento político. La advertencia de un filósofo de nuestro tiempo de que no hay ninguna garantía de que la verdad, si la llegáramos a descubrir, va a ser interesante, se aplica con particular intensidad al ámbito del financiamiento político. Aunque se sabe mucho menos del tema de lo que sería conveniente para la democracia, lo que se sabe con cierta rigurosidad tiende a mostrar que el dinero rara vez determina los resultados políticos y que los instrumentos para regular su influencia en la política pocas veces logran algo más que un éxito moderado y transitorio.

La experiencia internacional sugiere que si los esfuerzos regulatorios en materia de financiamiento político han de alcanzar, al menos, ese modesto nivel de éxito, los actores políticos que emprenden esta tarea deben observar algunas reglas básicas.

\section{Haga las preguntas correctas}

La enumeración de riesgos serios y recurrentes para la democracia realizada en la parte inicial de este trabajo plantea otras tantas preguntas fundamentales, que deberían servir como una suerte de guía para casi cualquier esfuerzo normativo en este campo, ciertamente en América Latina. Esas preguntas, son, al menos, seis:

- ¿Cómo minimizar el riesgo de la entrada de fuentes de financiamiento cuestionables en los partidos y campañas?

- ¿Cómo minimizar el riesgo de que, como consecuencia de la búsqueda de recursos para las campañas o las actividades partida- 
rias, emerjan conflictos de interés para los tomadores de decisión o que, si emergen, no sean detectados por los ciudadanos o la prensa?

- ¿Cómo minimizar el riesgo de la utilización electoral de recursos públicos por parte de las autoridades del gobierno?

- ¿Cómo generar condiciones en las que un grupo adecuadamente amplio de partidos o candidatos tengan una posibilidad mínima de hacer llegar su mensaje a los votantes?

- ¿Cómo generar condiciones para que la regulación del financiamiento político no alimente la inestabilidad del sistema de partidos y contribuya a la institucionalización de los partidos?

- ¿Cómo crear condiciones para que la legislación sobre financiamiento político se aplique eficazmente?

Cada una de estas seis preguntas apunta a un tema fundamental para la salud de la democracia, desde la integridad de los tomadores de decisión, hasta la equidad electoral y la credibilidad de las leyes. Es virtualmente imposible que alguna reforma pueda acometer todas estas necesidades simultánea, plena o siquiera coherentemente. En todo caso, no todas son igualmente prioritarias en todos los contextos. Por eso, es fundamental que toda reforma se sustente en un diagnóstico medianamente riguroso de lo que urge modificar.

Iniciar un proceso de reforma con una postura a priori sobre lo que debe ser reformado y cómo reformarlo, sin haber realizado primero un diagnóstico, constituye un grave error que termina por obstruir el proceso de negociación política que requiere la adopción y aplicación exitosa de los cambios normativos.

\section{Pregúntese si los fundamentos están en su lugar}

Si bien las dificultades para regular el financiamiento político son comunes a todas las democracias, se plantean en forma más clara en las democracias en vías de desarrollo o en los casos de países que están experimentando transiciones democráticas. Como lo han dicho agudamente Torres Rivas y Aguilar en un estudio de caso sobre Guatemala, la investigación y regulación del financiamiento electoral están fundamentadas en "supuestos de modernidad". ${ }^{55}$ Esto es, suponen la exis-

${ }^{55}$ Torres Rivas, Edelberto y Aguilar, Carla, "Financiación de partidos y campañas 
tencia de instituciones electorales y contraloras consolidadas, partidos políticos con un mínimo de institucionalización, y una prensa hábil, diligente e independiente que se encuentre protegida de la intimidación política. La regulación del financiamiento político demanda no sólo paciencia sino prestar atención a aspectos políticos muy básicos, sin los cuales está condenada al fracaso. Se trata, de algún modo, de una reforma política de "segunda generación" que los sistemas democráticos sólo pueden razonablemente emprender una vez que tareas básicas como el empadronamiento de la ciudadanía o la eliminación del fraude electoral ya han sido completadas exitosamente.

\section{Cuestione las verdades convencionales}

A su sentido de urgencia, los reformadores deben añadir un cierto escepticismo que les permita revisar algunas de las más extendidas creencias en materia de financiamiento político, que frecuentemente confunden más de lo que iluminan y distorsionan más de lo que describen. La falta de evidencia clara no obsta para que algunas aseveraciones tengan efectos políticos muy reales y terminen orientando los esfuerzos regulatorios.

Entre las verdades convencionales que deben ser examinadas con cuidado está la noción de que el costo de las campañas electorales está aumentando escandalosamente, que la televisión es la responsable de su aumento, que el financiamiento político explica los resultados electorales, que las contribuciones políticas explican las grandes políticas públicas, que las contribuciones privadas compran regularmente las decisiones políticas y que cuando un donador político recibe un beneficio la contribución es la causa de ese quid pro quo. ${ }^{56}$

Todas estas afirmaciones apuntan a problemas muy importantes, que merecen ser discutidos. Sin embargo, en torno a todas ellas, en diferentes grados, existe evidencia controvertida. Cada una de ellas puede o no ser cierta en una circunstancia específica, pero casi con seguri-

electorales: el caso guatemalteco", en Castillo, Pilar del y Zovatto, Daniel (eds.), La financiación de la política en Iberoamérica, San José, IIDH-CAPEL, 1998, p. 283.

56 Véase entre muchos, "Regulando el financiamiento político en Costa Rica: algunas reflexiones prácticas”, en Prado, Mimi (ed.), Modernización del Estado costarricense, San José, Centro Internacional para el Desarrollo Humano-Fundación Honrad Adenauer, 2004, pp. 254-259; Smith, Bradley, Unfree Speech: The Folly of Campaign Finance Reform, Princeton, Princeton University Press, 2001, pp. 39-65; Sorauf, op. cit., pp. 161-190. 
dad no será cierta en todas partes. Hacen mal los reformadores cuando asumen que lo es. Se vuelve a plantear, así, un punto ya mencionado: nada sustituye al diagnóstico como base de toda reforma. Y no cualquier diagnóstico, sino uno fundado en evidencia empírica y métodos rigurosos.

4. Aproveche las crisis

Si algo ha mostrado reiteradamente la experiencia internacional es que los intentos para reformar integralmente las reglas de financiamiento político rara vez ocurren en forma espontánea, preventiva o inevitable. Tanto en las democracias desarrolladas como en vías de desarrollo, la experiencia ha mostrado que tales reformas casi siempre son el resultado de escándalos y crisis que ponen el tema en el centro del debate político. La crisis suele ser la madre de la reforma (o al menos su "partera") y la mejor aliada de quienes tienen genuino interés en mejorar la regulación vigente.

\section{Legisle pensando en el largo plazo, pero revise en el corto plazo}

Si las crisis sobrevinientes pueden ser disparadoras de la reforma, no es conveniente que definan exclusivamente su contenido. La experiencia comparada aconseja evitar cambios en las reglas político-electorales para responder a hechos variables y coyunturales, exclusivamente a problemas del momento. Aunque esos problemas tiñen todo esfuerzo regulatorio, es preciso aquilatarlos en su verdadera dimensión.

La reforma del financiamiento político debe basarse en una mirada estratégica de mediano y largo plazo. La política - como la economía - demanda una visión de futuro, basada en un conjunto de reglas de juego claras y estables. Piénsese en la cadena de fenómenos que un cambio en las reglas de financiamiento trae aparejado: adecuación de las maquinarias partidarias al nuevo sistema, incluyendo nuevas formas de relacionarse con los electores; ajuste de los medios de comunicación a nuevas formas de hacer política, y adecuación de las estructuras de administración de la autoridad electoral a la nueva realidad, por citar sólo algunos de los cambios más notorios. ${ }^{57}$ Esto no puede, ni debe estar cambiando radicalmente en cada campaña.

${ }^{57}$ Perelli, Carina, "Reformas a los sistemas electorales: algunas reflexiones desde la 
Sin embargo, será inevitable hacer ajustes y hay que estar abierto a ellos. La regulación del financiamiento político es conocida en Alemania como la "legislación interminable". Todo reformador debe estar muy consciente del carácter tentativo de sus esfuerzos y de la necesidad de revisarlos periódicamente. Este es, en palabras de Zovatto, un tema condenado a la sucesión de distintas reformas legales, de ahí la importancia de tener en cuenta su carácter fluctuante y coyuntural. ${ }^{58}$ Nuevas fuentes y prácticas de financiamiento sustituirán a las anteriores y formas inesperadas de vulnerar la legislación vigente serán invariablemente desarrolladas por los actores políticos. Al igual que la propia construcción de la democracia, la configuración de un sistema efectivo de financiamiento político es un proceso dinámico, una larga travesía en la que muy pocas estaciones serán éxitos rotundos.

\section{Preste atención a la combinación de instrumentos y al entorno institucional}

Cada uno de los instrumentos de regulación del financiamiento político — en particular los sistemas de financiamiento estatal- admite muchas variaciones y está ligado a un entorno normativo mucho más amplio que condiciona sus efectos. La evidencia disponible advierte contra la tentación de hacer afirmaciones empíricas generales sobre los efectos de cada instrumento de regulación. Prestar atención a la combinación de normas es crucial para predecir con algún nivel de precisión los efectos de las normas de financiamiento político. Olvidar esto es una receta para las prescripciones equivocadas y las sorpresas desagradables.

Aún más, en algunos casos las medidas requeridas para enfrentar algunos de los dilemas fundamentales del financiamiento político no serán consistentes con las requeridas para lidiar con otros. Algunos pasos necesarios para mejorar la calidad de la competencia electoral, por ejemplo, no necesariamente serán compatibles con el imperativo de no alimentar la inestabilidad del sistema de partidos. En esto, como en tantas otras cosas, se aplica la vieja regla de vida de que no todas las cosas buenas vienen juntas.

práctica”, Revista de Ciencia Política, Pontificia Universidad Católica de Chile, vol. 26, núm. 1, 2006.

${ }^{58}$ Griner y Zovatto, op. cit., p. 335. 
De la misma manera es vital prestar atención al entorno político e institucional en el que se introducen las regulaciones del financiamiento político. Factores como el tipo de régimen, el sistema electoral, la presencia de estructuras unitarias o federales, la fragmentación del sistema de partidos, el arraigo de las identidades partidarias, el alcance y profundidad de la intervención estatal, y las prerrogativas judiciales, para mencionar unos pocos, moldean decisivamente los incentivos y necesidades financieras de los actores políticos, los obstáculos para monitorear los flujos de contribuciones y gastos, y, en última instancia, los efectos de cualquier sistema de financiamiento político. Así, por ejemplo, los sistemas electorales orientados a las candidaturas individuales, los sistemas de voto preferencial, las estructuras federales y los sistemas de partidos altamente fragmentados inciden en un aumento en el número de estructuras de campaña y reducen las economías de escala que son inherentes a modelos más centralizados. Al multiplicar los puntos de entrada y salida del dinero y, por ello, los obstáculos para aplicar controles financieros, las estructuras electorales descentralizadas requieren de un marco regulatorio diferente que el que precisa un sistema basado en listas partidarias cerradas en un país con estructura unitaria. La tarea de diseñar regulaciones adecuadas al financiamiento político requiere, pues, que los reformadores comprendan los vínculos que ligan las reglas de financiamiento político a su entorno institucional y político.

Una mención particular merece el creciente papel que en esta materia están jugando los tribunales o cortes constitucionales, que pueden condicionar decisivamente el rango de opciones existentes para una reforma. Ha sido así en los casos de Alemania, Estados Unidos y Costa Rica, donde la jurisprudencia constitucional no sólo ha dado lugar a modificaciones drásticas de las regulaciones, sino que ha creado un marco referencial obligatorio para todas las reformas posteriores ${ }^{59} \mathrm{En}$

59 Véase Corrado, Anthony et al. (eds.), Campaign Finance Reform: A Sourcebook, Washington D. C., Brookings Institution Press, 1997, capítulos 2-3; Ewing, Keith D., Money, Politics and Law: A Study of Electoral Campaign Finance Reform in Canada, Oxford, Clarendon Press, 1992; Sorauf, op. cit.; Gunlicks, Arthus, "The New German Party Finance Law”, German Politics, vol. 4, núm. 1, abril de 1995; González-Varas, Santiago, La financiación de los partidos políticos, Madrid, Dykinson, 1995; Pulzer, Peter, "Votes and resources: Political finance in Germany", German Politics and Society, vol. 19, núm. 1, primavera de 2001; Casas-Zamora, Kevin, "Contribución estatal a los partidos políticos en Costa Rica: apuntes sobre sus efectos en la dinámica del sistema de partidos", en Rovira, Jorge (ed.), La democracia de Costa Rica ante el siglo XXI, San José, Editorial 
aquellos casos donde opera la jurisdicción constitucional, considerar la jurisprudencia de esta última en los procesos de reforma es imprescindible para no promulgar disposiciones destinadas inexorablemente a su anulación.

Comprender el entorno institucional no hace de la predicción de los efectos de una reforma una ciencia exacta, ni cosa parecida. Con toda seguridad, toda reforma acabará por generar consecuencias imprevistas y, casi siempre, no deseadas. Tener la humildad y la sabiduría para revisar con alguna regularidad las normas introducidas es, por ello, esencial.

\section{Sea moderado}

Si bien es cierto que tratándose de la regulación del financiamiento político no existe nada que sustituya la aplicación efectiva de la ley, es igualmente cierto que la medicina regulatoria debe tomarse en dosis cuidadosamente administradas. La historia no ha tratado con amabilidad los intentos de introducir normas draconianas para regular el financiamiento político. Como se mencionó más arriba, los topes generales de gasto, por ejemplo, han demostrado ser de difícil aplicación y han acumulado una larga historia de fracasos en países que van desde los Estados Unidos hasta Japón. Lo mismo puede decirse de los intentos de instaurar prohibiciones absolutas de las contribuciones privadas. En los pocos casos en que los reformadores han tratado de hacerlo - como en la India y Francia-, han recibido sorpresas desagradables: las contribuciones privadas han continuado realizándose pero en formas singularmente corruptas y opacas, obligando a los reformadores a volver sobre sus pasos y a re legalizar los aportes privados. Yace aquí una lección crucial: entre más difícil se haga a los partidos y candidatos recaudar fondos por vías legales, más probable será que lo hagan mediante procedimientos oscuros y cuestionables.

\section{Busque aliados y construya consensos}

La reforma de las reglas de financiamiento político no es simplemente un problema técnico sino, ante todo, político. Generalmente los refor-

Universidad de Costa Rica-Fundación Friedrich Ebert, 2001; id., "Regulando el financiamiento político..., op. cit., y id., Paying for Democracy..., cit. 
madores se mueven en un angosto espacio en el que deben acometer dos tareas a veces incompatibles: por un lado, la de construir amplias coaliciones que pongan presión sobre quienes se benefician del statu quo - típicamente los partidos establecidos-y, por otro, la de involucrar tanto como sea posible en la elaboración de la reforma a los partidos políticos. Estos últimos casi siempre resisten cualquier proceso tendiente a cambiar las condiciones de la competencia democrática e invariablemente tratarán de hacer fracasar aquella legislación que les sea impuesta en forma inconsulta. Tampoco debe olvidarse nunca que, antes que nadie, los personeros de los partidos son los verdaderos expertos en materia de financiamiento político. Ese caudal de experiencia no debe ser desaprovechado por ninguna reforma.

Todo esto requiere ciertamente buscar aliados dentro y fuera del sistema político. La prensa independiente, que ha demostrado ser acaso el más poderoso control sobre las prácticas cuestionables de financiamiento político en muchas democracias, puede ser un aliado particularmente poderoso en esta materia. Pero sobre todo requiere concebir la reforma como un proceso basado en el diálogo y el consenso en el cual participe el más amplio espectro posible de actores políticopartidarios y en el que sean involucrados y consultados diferentes sectores sociales. Esto permitirá que la reforma que se adopte adquiera, además de un alto nivel de legitimidad, sostenibilidad en el tiempo.

\section{Acompañe la reforma con recursos adecuados}

Todo sistema efectivo para regular el financiamiento político debe venir aparejado de recursos económicos, humanos y jurídicos para aplicarlo, si no ha de perder totalmente su credibilidad. Este punto es particularmente relevante en América Latina, donde existe una enorme propensión a creer que la introducción de cambios en los estatutos legales garantiza por sí misma su impacto en la realidad. El caso de México, ya mencionado antes, muestra que es posible acometer con relativo éxito la creación de controles al financiamiento político, pero que ello requiere de instituciones robustas y de muchos recursos. Que no se olvide: las reformas fallidas son más que simplemente inocuas; por el contrario, alimentan el desencanto político de la ciudadanía y afectan la credibilidad de futuros esfuerzos de regulación. 


\section{Sea realista}

Esta es, acaso, la lección más importante. Es razonable esperar que regulaciones bien concebidas y aplicadas puedan reducir significativamente las prácticas de financiamiento político más cuestionables y riesgosas para la democracia. Sin embargo, creer que la introducción de esas regulaciones será capaz de erradicar, de una vez y para siempre, las patologías del financiamiento político es absurdo y contraproducente. Quienes aspiren a elaborar reformas en esta materia no deben abrigar grandes ilusiones sobre las victorias que les esperan como resultado de sus empeños. Después de todo, existe muy poca evidencia de que la introducción y aun la cabal puesta en práctica de controles sobre el financiamiento político sirven para aumentar dramáticamente la legitimidad de los sistemas políticos o la imagen pública de los reformadores. La lucha para limpiar las prácticas de financiamiento político es, en el mejor de los casos, un camino entre riscos. Cuando se encuentran desprovistas de regulación, tales prácticas alimentan sospechas generalizadas y dañinas mitologías; cuando se les regula inadecuadamente, generan desencanto con las reformas y escepticismo de las intenciones de los políticos que las introdujeron; cuando se les regula rigurosamente, producen escándalos recurrentes sobre métodos cuestionables de financiamiento y, en consecuencia, mayor cinismo político. Así, los autores de reformas al financiamiento político pueden fracasar hasta cuando tienen éxito. Por admirables que sean nuestras ambiciones, es importante comprender que la reforma al financiamiento político no es más que un intento por limitar los daños infligidos a valores democráticos centrales por el ineludible papel del dinero en la política.

Las lecciones anteriores no constituyen un llamado a la inacción, sino sólo un sutil recordatorio de las grandes dificultades que aguardan a los reformadores en este campo. A pesar de los obstáculos, no queda más camino que emprender la tarea de reforma, sobre todo en América Latina, toda vez que los daños derivados de la desregulación del financiamiento político son mucho más grandes que los derivados de todas las demás opciones. Por ello, a manera de conclusión, conviene hacer una enumeración de algunas medidas de regulación del financiamiento político que, en términos generales, han mostrado su utilidad en diversos contextos y cuya adopción, por ello, debe ser al menos considerada por los sistemas políticos de América Latina. 


\section{V. ¿Hacia dónde ir? Algunas propuestas de reforma}

Asumiendo que existen la voluntad y los recursos para hacer funcionar un sistema riguroso de control del financiamiento político, la experiencia internacional y el elenco de riesgos que enfrentan en materia de financiamiento político las democracias latinoamericanas, esbozado en las páginas anteriores, sugieren la conveniencia de introducir algunos instrumentos regulatorios como los siguientes:

- Mayor control del financiamiento privado, con prohibición de las donaciones anónimas, de personas jurídicas y de fuentes extranjeras, principalmente.

- Sistema de subvención pública que garantice acceso a los partidos y candidatos, en condiciones de equidad, a recursos adecuados para financiar sus actividades ordinarias y electorales. Para ello es conveniente adoptar:

- Barreras razonables de acceso al subsidio, que no propendan a la atomización del sistema de partidos, pero que tampoco dificulten excesivamente la obtención del financiamiento público por parte de partidos minoritarios o emergentes.

- Reglas de periodicidad de la entrega del subsidio estatal, de manera que el desembolso de una parte sustancial de los recursos se realice en cuotas a lo largo de todo el ciclo electoral y se dirija, parcialmente, a tareas de investigación, formación y capacitación partidaria.

- Reglas para el adelanto parcial y sustancial del subsidio electoral, respaldado por garantías otorgadas por los partidos y candidatos receptores, con posibilidades de acceso para los partidos y candidatos sin pasado electoral.

- Subsidios limitados para los procedimientos electorales internos de los partidos, particularmente cuando se trate de procedimientos abiertos a la participación del electorado.

- Reglas de distribución del subsidio que combinen:

- La asignación de una parte de los recursos en forma igualitaria entre todos los receptores elegibles. 
- La asignación de una parte en forma proporcional a la votación o la distribución de escaños.

- La asignación de una parte del subsidio de acuerdo a los esfuerzos realizados por los partidos y candidatos para recaudar donaciones menores a cierto monto, mediante un sistema de matching grants.

- Adopción de controles sobre algunos disparadores del gasto electoral, por ejemplo:

- Limitación de la duración de las campañas electorales, particularmente del periodo de emisión de la publicidad electoral.

- Topes a la emisión de publicidad por parte de partidos y candidatos en medios de comunicación.

- Facilitación de espacios publicitarios en la televisión pública y privada a los partidos políticos, asegurando que al menos una parte de esos espacios se distribuya en forma igualitaria entre todos los contendientes. Esos espacios deberán ser otorgados gratuitamente por los concesionarios de las frecuencias o, alternativamente, podrán ser adquiridos por la autoridad electoral y puestos a disposición de los partidos.

- Adopción de mecanismos de rendición de cuentas, transparencia y publicidad del manejo financiero de partidos y candidatos, mediante medidas como las siguientes:

- Individualización de la responsabilidad financiera de las campañas, mediante la creación de la figura del agente electoral, de acatamiento obligatorio para todos los partidos a todo nivel.

- Establecimiento de la obligación de los partidos de reportar periódicamente todos sus ingresos a la autoridad electoral (o autoridad competente en la materia), incluyendo las contribuciones en especie (con excepción del trabajo voluntario).

- Imposición a los medios de comunicación de la obligación de reportar las tarifas y descuentos concedidos a todos los partidos y candidatos.

- Otorgamiento expreso a la autoridad electoral (o autoridad competente en la materia) de la potestad legal de auditar los reportes financieros de los partidos y candidatos. Ello implica: 
- La potestad de llevar a cabo todas aquellas actividades necesarias para establecer la veracidad de su contenido, incluyendo procedimientos de auditoría in situ y aleatoria de los reportes financieros presentados.

- La potestad de instruir procesos en caso de detectarse violaciones a las regulaciones existentes.

- Fortalecimiento humano y material de las instancias encargadas de supervisar el financiamiento político.

- Establecimiento explícito del carácter público de la información de financiamiento político y, consecuentemente, de mecanismos de consulta por parte de la prensa y el público de los reportes financieros presentados por los partidos y candidatos, así como de los resultados de las auditorías realizadas por la autoridad electoral (o autoridad competente en la materia).

- Publicación en Internet y en al menos un diario de circulación nacional de una lista resumida con las principales fuentes de ingreso de cada partido y candidato, y las conclusiones de los reportes de las auditorías realizadas por la autoridad electoral.

- Establecimiento de un sistema gradual de sanciones a los responsables financieros de los partidos en los casos de incumplimiento de la legislación vigente. Ese sistema deberá incluir:

- La retención de los subsidios estatales.

- Establecimiento de multas y penas de prisión para los responsables financieros de los partidos.

- La disolución del partido y la revocación de la credencial de funcionarios electos por sufragio popular como sanción para las violaciones reiteradas y de excepcional gravedad.

- Fortalecimiento del órgano de control: el control en materia de financiamiento, demanda una autoridad autónoma, tanto en términos políticos como financieros, e investida con suficientes potestades legales para supervisar, verificar, investigar $y$, de ser necesario, instruir procesos, por lo cual es fundamental dotar a los órganos de control de las facultades y recursos necesarios para efectuar eficazmente su labor.

Ninguna de las anteriores sugerencias está exenta de controversia, que será mayor cuanto más profundice en el detalle de su diseño constitu- 
cional, legislativo o reglamentario, según sea el caso. Asimismo, es evidente que esta lista de propuestas no constituye un paquete monolítico que precise ser adoptado en su totalidad. Por el contrario, la experiencia comparada advierte sobre la conveniencia, incluso la inevitabilidad, de proceder pacientemente, por aproximaciones sucesivas, dando prioridad a los cambios más urgentes y más dotados de consenso político.

Lo realmente crucial es que las reformas adoptadas, cualesquiera que sean, vayan acompañadas de los recursos para aplicarlas rigurosamente, de la voluntad de revisarlas cuando muestren sus inevitables limitaciones y del realismo para entender que ningún sistema de financiamiento político, por sofisticado que sea, es capaz de garantizar por sí mismo la integridad y la transparencia de la actividad política.

\section{Vl. Bibliografía}

Ammar, Dina, "Public Funding of Political Parties: The Case of Egypt", Documento preparado para la Conferencia sobre Integridad Política organizada por el Al Ahram Center for Political and Strategic Studies; Cairo, Egipto, 12 y 13 de enero de 2008.

Amr, Dima y Lisowski, Rainer, "Political finance in Old Dominions: Australia and Canada", en NAssmacher, Karl-Heinz, Foundations for Democracy: Approaches to Comparative Political Finance, Baden-Baden, Nomos, 2001.

Ansolabehere, Stephen et al. , "Corruption and the Growth of Campaign Spending”, en Lubenow, Gerald C. (ed.), A User's Guide to Campaign Finance Reform, Oxford, Rowman \& Littlefield Publishers, 2001.

Arredondo Ramírez, Pablo, "Los medios de comunicación y la contienda electoral", Renglones, núm. 46, agosto-noviembre de 2000.

AvrIL, Pierre, "Regulation of political finance in France", en HerBert, Alexander y Rei Shiratori, Rei (eds.), Comparative Political Finance among the Democracies, Boulder, Westview Press, 1994.

Blechinger, Verena y Nassmacher, Karl-Heinz, "Political finance in non-Western democracies: Japan and Israel", en NAssmacher, Karl-Heinz, Foundations for Democracy: Approaches to Comparative Political Finance, Baden-Baden, Nomos, 2001. 
Carrillo, Manuel et al., Dinero y contienda político-electoral: reto de la democracia, México, Fondo de Cultura Económica, 2003.

Casas-Zamora, Kevin, "Contribución estatal a los partidos políticos en Costa Rica: apuntes sobre sus efectos en la dinámica del sistema de partidos", en Rovira, Jorge (ed.), La democracia de Costa Rica ante el siglo XXI, San José, Editorial Universidad de Costa RicaFundación Friedrich Ebert, 2001.

- - - "Financiamiento de campañas en Centroamérica y Panamá", Cuadernos de CAPEL, San José, núm. 48, 2003.

- _ - "Regulando el financiamiento político en Costa Rica: algunas reflexiones prácticas”, en PrAdo, Mimi (ed.), Modernización del Estado costarricense, San José, Centro Internacional para el Desarrollo Humano-Fundación Honrad Adenauer, 2004.

-_- Paying for Democracy: Political Finance and State Funding for Parties, Colchester, European Consortium for Political Research, 2005.

"Caso maletín: cuatro detenidos en EE.UU., BBC Mundo.com, 13 de diciembre de 2007. http://news.bbc.co.uk/hi/spanish/latin_americal news id_7141000/7141500.stm.

Cepeda-UlloA, Fernando, Financiación de campañas politicas, Bogotá, Ariel, 1997.

"Conviction in Spy Case Over Cash-Filled Suitcase", The New York Times, 3 de noviembre de 2008.

Córdova, Lorenzo, "La reforma electoral de 2007-2008: Reporte ejecutivo", documento inédito, 2008.

- - - y Murayama, Ciro, Elecciones, dinero y corrupción: Pemexgate y Amigos de Fox, México, Cal y Arena, 2006.

Corrado, Anthony et al. (eds.), Campaign Finance Reform: A Sourcebook, Washington D. C., Brookings Institution Press, 1997.

Calle, Humberto de la, "Financiación de los partidos políticos y las campañas electorales en Colombia", en CAstillo, Pilar del y Zovatto, Daniel (eds.), La financiación de la política en Iberoamérica, San José, IIDH-CAPEL, 1998.

Castillo, Pilar del y Zovatto, Daniel (eds.), La financiación de la política en Iberoamérica, San José, IIDH-CAPEL, 1998.

Doublet, Yves-Marie, L’Argent et la Politique en France, París, Económica, 1997.

"Drugs are back"; The Economist, 25 de mayo de 1996.

EL Panamá América, Panamá, 14 de agosto de 2001. 
"El 'Pemexgate', una novela de no-ficción”, Proceso, México, 13 de octubre de 2002.

"European Politics Plagued by Funding Scandals", The Guardian, 4 de diciembre de 1999.

EwIng, Keith D., Money, Politics and Law: A Study of Electoral Campaign Finance Reform in Canada, Oxford, Clarendon Press, 1992.

"Exigen ley que regule uso de recursos públicos en campaña”, El Universal, Caracas, 21 de febrero de 2009

Federal Election Commission, Annual Report 1997, Washington D. C., Federal Election Commission, 1998.

- - - "Alternative Dispute Resolution Program", 2002, http://www. fec.gov/pages/brochures/adr.shtml\#What\%20is\%20ADR.

Ferreira Rubio, Delia, "El control del financiamiento de los partidos en Argentina: ¿Qué cambió con la nueva ley?”, Buenos Aires, Universidad del CEMA, Serie Documentos de Trabajo núm. 292, 2005.

_-_, "Financiamiento de los partidos políticos en Argentina"; presentación realizada en el seminario "La legislación comparada sobre financiación de los partidos políticos", Montevideo, Uruguay, 27 y 28 de noviembre de 2007.

Galiardo, Juan Luis y Berbell, Carlos, FILESA: Las tramas del dinero negro en la política, Madrid, 1995.

García-Laguardia, Jorge Mario, "Constitucionalización de los partidos políticos”, Diccionario Electoral, San José, CAPEL-IIDH (1989).

GedDEs, Barbara y Ribeiro-Neto, Artur, "Institutional sources of corruption in Brazil”, Third World Quarterly, vol. 13, núm. 4, 1992.

Gidlund, Gullan y Koole, Ruud, "Political Finance in North of Europe: The Netherlands and Sweden”, en Nassmacher, Karl-Heinz, Foundations for Democracy: Approaches to Comparative Political Finance, Baden-Baden, Nomos, 2001.

Gómez Castellanos, Rodolfo, Mercadotecnia política: uso y abuso en los procesos electorales, México, Universidad Autónoma de Baja California, 2006.

González-Varas, Santiago, La financiación de los partidos políticos, Madrid, Dykinson, 1995.

Gray, Bill, ex-Comisionado Electoral de Australia; entrevista, Ciudad de México, 6 de junio de 2001.

Griner, Steven y Zovatto, Daniel (eds.), De las normas a las buenas prácticas: el desafío del financiamiento político en América Latina, San José, OEA-IDEA, 2004. 
- - - "Lectura regional comparada", en Griner, Steven y ZovatTo, Daniel (eds.), De las normas a las buenas prácticas: el desafío del financiamiento político en América Latina, San José, OEA-IDEA, 2004. Gross, Kenneth A., "The Enforcement of Campaign Finance Rules: A System in Search of Reform”, en Corrado, Anthony et al. (eds.), Campaign Finance Reform: A Sourcebook, Washington D. C., Bookings Institution Press, 1997.

Gunlicks, Arthus, “The New German Party Finance Law”, German Politics, vol. 4, núm. 1, abril de 1995.

"Héctor Murguía: los narcos en casa", El Universal, México, 27 de marzo de 2009.

Hofnung, Menachem, "The Public Purse and the Private Campaign: Political Finance in Israel", Journal of Law and Society, vol. 23, núm. 1, marzo de 1996.

- _ - , profesor del Departamento de Ciencia Política, Universidad Hebrea de Jerusalem, ex-miembro del Comité Directivo del Partido Meretz (Israel); entrevista, Ciudad de México, 7 de junio de 2001.

JAIN, Randhir, profesor del Departamento de Ciencias Políticas, Universidad de Dehli, India; entrevista, Ciudad de México, 6 de julio de 2001.

Jacobson, Gary, "Money and Votes Reconsidered: Congressional Elections, 1972-1982”, Public Choice, vol. 47, núm. 1, 1985.

Jordan, David C., Drug Politics: Dirty Money and Democracies, Norman, University of Oklahoma Press, 1999.

Katz, Richard S. y Kolodny, Robin, "Party Organization as an Empty Vessel: Parties in American Politics", en Katz, Richard S. y MaIr, Peter (eds.), How Parties Organize: Change and Adaptation in Party Organizations in Western Democracies, Londres, Sage, 1994.

Kinzo, María D’Alva, "Funding Parties and Elections in Brazil", en Burnell, Peter y Ware, Alan (eds.), Funding Democratization, Manchester, Manchester University Press, 1998.

KleE, Gudrun, "Financing Parties and Elections in Small European Democracies: Austria and Sweden", en Gunlicks, Arthur (ed.), Campaign and Party Finance in North America and Western Europe, Boulder, Westview Press, 1993.

Koole, Ruud, "Political finance in Western Europe: Britain and France", en Nassmacher, Karl-Heinz, Foundations for Democracy: Approaches to Comparative Political Finance, Baden-Baden, Nomos, 2001. 
La Prensa de Panamá, Panamá, 22 de julio de 1995.

LaAkso, Marku y TaAgePera, Rein, "Effective Number of Parties: A Measure with Application to Western Europe", Comparative Political Studies, vol. 12, núm. 1, abril de 1979.

Levush, Ruth et al., Campaign Financing of National Elections in Foreign Countries, Washington D. C., Law Library of Congress, 1991.

MADRID, Raúl, "Ethnic Cleavages and Electoral Volatility in Latin America and the Caribbean", Comparative Politics, vol. 38, octubre de 2005.

MaInWARING, Scott y Scully, Timothy, "Introduction: party systems in Latin America”, en MaInwaring, Scott y Scully, Timothy (eds.), Building Democratic Institutions: Party Systems in Latin America, Stanford, Stanford University Press, 1995.

"Maletín: apuntan al gobierno venezolano", BBC Mundo.com, 17 de octubre de 2008, http://news.bbc.co.uk/hi/spanish/latin_america/new sid_7677000/7677327.stm.

MAYOrga, René, "El financiamiento de los partidos políticos en Bolivia”, en Castillo, Pilar del y Zovatto, Daniel (eds.), La financiación de la política en Iberoamérica, San José, IIDH-CAPEL, 1998.

MворJ, El Hadj, profesor del Departamento de Derecho, Universidad Cheikh Anta Diop University, Senegal; entrevista, Ciudad de México, 8 de junio de 2001 .

Mendilow, Jonathan, "Public Party Funding and Party Transformation in Multiparty Systems", Comparative Political Studies, vol. 25, núm. 1, abril de 1992.

Miró Quesada, Francisco, "Financiamiento de partidos políticos y las campañas electorales en el Perú", en CAstillo, Pilar del y Zovatto, Daniel (eds.), La financiación de la política en Iberoamérica, San José, IIDH-CAPEL, 1998.

Müller, Wolfgang, "The Development of Austrian Party Organizations in the Post-War Period", en Katz, Richard S. y MaIR, Peter (eds.), How Parties Organize: Change and Adaptation in Party Organizations in Western Democracies, Londres, Sage, 1994.

Nassmacher, Karl-Heinz, "Political finance in West Central Europe: Austria, Germany, Switzerland”, en Nassmacher, Karl-Heinz, Foundations for Democracy: Approaches to Comparative Political Finance, Baden-Baden, Nomos, 2001.

NúÑEZ, Arturo, "Análisis comparativo sobre financiamiento de campañas y partidos políticos en México", ponencia presentada en el 
Taller sobre Financiamiento Político organizado por la Organización de Estados Americanos e International IDEA, San José, Costa Rica, 8-9 de agosto de 2003.

Orozco, Jesús, "Financiamiento y fiscalización de los partidos políticos en México", en Fontaine, Arturo et al. (eds.), Reforma de los partidos políticos en Chile, Santiago, PNUD-CEP-Libertad y Desarrollo-CIEPLAN, 2008.

Pajares-Montolío, Emilio, La financiación de las elecciones, Madrid, Congreso de los Diputados, 1998.

PARK, Chan Wook, "Financing Political Parties in South Korea: 19881991”, en Alexander, Herbert y Shiratori, Rei (eds.), Comparative Political Finance among the Democracies, Boulder, Westview Press, 1994.

Payne, Mark et al., La política importa. Democracia y desarrollo en América Latina, Washington D. C., BID-IDEA, 2006.

Perelli, Carina, "Reformas a los sistemas electorales: algunas reflexiones desde la práctica", Revista de Ciencia Política, Pontificia Universidad Católica de Chile, vol. 26, núm. 1, 2006.

Pinto-Duschinsky, Michael, "Financing Politics: A Global View”, Journal of Democracy, vol. 13, núm. 4, octubre de 2002.

Pollock, James Kerr, Money and Politics Abroad, Nueva York, Alfred A. Knopf, 1932.

Pujas, Veronique y Rhodes, Martin, Party Finance and Political Scandal in Latin Europe, Florence, European University Institute, Robert Schuman Centre, 1998.

Pulzer, Peter, "Votes and resources: Political finance in Germany", German Politics and Society, vol. 19, núm. 1, primavera de 2001.

Rabie, Amr Hashem, "Financing Egyptian Political Parties", ponencia presentada en la Conferencia sobre Integridad Política organizada por el Al Ahram Center for Political and Strategic Studies; Cairo, Egipto, 12-13 de enero de 2008.

"Registran candidatura de Héctor Murguía", El Diario (Ciudad Juárez), 23 de abril de 2009.

Rhodes, Martin, "Financing Party Politics in Italy: a Case of Systemic Corruption”, West European Politics, vol. 20, núm. 1, enero (1997).

Rodríguez Raga, Juan Carlos y Botero, Felipe, “Ordenando el caos: Elecciones legislativas y reforma electoral en Colombia”, Revista de Ciencia Política, Pontificia Universidad Católica de Chile, vol. 26, núm. 1, 2006. 
Royal Commission on Electoral Reform and Party Financing, Reforming Electoral Democracy: volume 1, Canada, Royal Commission on Electoral Reform and Party Financing, 1991.

"Russian Election Lacked 'Freedom,' Monitor Says", The Washington Post, 4 de marzo de 2008

Sartori, Giovanni, Partidos y sistemas de partidos, Madrid, Alianza Editorial, 1991.

Schattschneider, E. E., The Semi-Sovereign People, Fort Worth, Harcourt Brace Jovanovich College Publishers, 1975 [1960].

Smith, Bradley, Unfree Speech: The Folly of Campaign Finance Reform, Princeton, Princeton University Press, 2001.

Sorauf, Frank J., Inside Campaign Finance: Myths and Realities, New Haven, Yale University Press, 1992.

Stanbury, William T., "Financing federal politics in Canada in an era of reform", en Gunlicks, Arthur (ed.), Campaign and Party Finance in North America and Western Europe, Boulder, Westview Press, 1993.

Torres Rivas, Edelberto y Aguilar, Carla, "Financiación de partidos y campañas electorales: el caso guatemalteco", en CASTILlo, Pilar del y Zovatto, Daniel (eds.), La financiación de la política en Iberoamérica, San José, IIDH-CAPEL, 1998.

Transparency International, Global Corruption Report- 2004Londres, Pluto Press, 2004.

Tribunal Electoral del Poder Judicial de la Federación [TEPJF], Dictamen relativo al cómputo final de la elección de presidente de los Estados Unidos Mexicanos, declaración de validez de la elección y de presidente electo; Resolución del 5 de septiembre de 2006, México, http://www.trife.gob.mx/documentacion/publicaciones/Infor mes/DIC TAMEN.pdf.

Unión Europea, Misión de Observación Electoral de la Unión Europea, Informe Final Elecciones Parlamentarias-Venezuela 2005, http://www.sumate.org/Elecciones/2005Parlamentarias/2005_ informe_final_Union_Europea.pdf.

- _- Misión de Observación Electoral de la Unión Europea, Informe Final Elección Presidencial-Venezuela 2006, http://www. sumate.org/Elecciones/2006Presidenciales/2006_informe_final_Union_Euro pea.pdf.

VAldÉs Prieto, Salvador et al., "Proposiciones sobre el financiamiento de la actividad política”, Estudios Políticos, núm. 78, otoño de 2000. 
VAldéz Zepeda, Andrés, "México en su encrucijada: un análisis de la elección presidencial del 2006”, Contratexto digital, Universidad de Lima, Perú, año 4, núm. 5, 2006.

VARgas, Mauricio et al., El presidente que se iba a caer: Diario secreto de tres periodistas sobre el 8000, Bogotá, Planeta, 1996.

Vargas Llosa, Mario, El pez en el agua, Madrid, Alfaguara, 2005.

Walecki, Marcin, "Political finance in Central Eastern Europe", en Nassmacher, Karl-Heinz, Foundations for Democracy: Approaches to Comparative Political Finance, Baden-Baden, Nomos, 2001.

-_- Money and Politics in Poland, Warsaw, Institute of Public Affairs, 2005.

Welch, W. P., "The Effectiveness of Expenditures in State Legislative Races", American Political Quarterly, vol. 4, julio de 1976.

"Well I Never, Says the President", The Economist, 29 de junio de 1996. Woldenberg, José et al., "El modelo de financiación de los partidos políticos en México", en Castillo, Pilar del y Zovatto, Daniel (eds.), La financiación de la política en Iberoamérica, San José, IIDH-CAPEL, 1998.

Zovatto, Daniel, "La financiación de la política y su impacto en la ética de la administración pública en Latinoamérica", Revista Reforma y Democracia, Caracas, Centro Latinoamericano para el Desarrollo (CLAD), núm. 10, 1998.

- - - "La financiación de la política en Iberoamérica: una visión preliminar comparada”, en CAstillo, P. del y Zovatto, D. (edits.), La financiación de la política en Iberoamérica, San José, IIDH-CAPEL, 1998.

- _ , "La relación entre el dinero y la política: una lectura comparada latinoamericana", Seminario Internacional sobre legislación y organización electoral, Lima, Transparencia-OEA, 1999.

_- _, "Estudio comparado de las características jurídicas y prácticas del financiamiento de los partidos políticos y las campañas electorales en América Latina”, en Pretelt, J. y Ramírez, J. (comp.), Democracia política y electoral en América Latina, Bogotá, Universidad Sergio Arboleda-OEA, 2000.

- - - "Political Finance in Latin America", en Nassmacher, K. H., Foundations for Democracy: Approaches to Comparative Political Finance Essays, Baden Baden, 2001.

- - Dinero y política en América Latina: una visión comparada, Lima, Transparencia-International IDEA, 2003. 
-_- Dinero y política en América Latina: una visión comparada, ponencia presentada en la X Conferencia de Organismos Electorales de América del Sur, Lima, ONPE, 2003.

- - - "Estudios sobre financiamiento de partidos políticos en Centroamérica y Panamá", Cuadernos de CAPEL, núm. 48, San José, IIDH-CAPEL, 2003.

- - - "The Legal and Practical Characteristics of the Funding of Political Parties and Election Campaigns in Latin America", en Handbook on Funding of Political Parties and Election Campaigns, Sweden, International IDEA, 2003.

- - - "América Latina", en CARrillo, Manuel et al., Dinero y contienda político-electoral: reto de la democracia, México, Fondo de Cultura Económica, 2003.

- - - "Estudio comparado de las características jurídicas y prácticas del financiamiento de los partidos políticos y las campañas electorales en América Latina", en Alcántara, Manuel y Martínez Barahona, Elena (eds.), Política, dinero e institucionalización partidista en América Latina, México, Universidad Iberoamericana, Instituto Federal Electoral, Facultad Latinoamericana de Ciencias Sociales, 2003.

- - - Dinero y política en América Latina: una visión comparada, San José, Flacso, 2004.

- - - "Dinero y política en América Latina", Foreign Affairs en español, México, ITAM, vol. 5, núm. 4, 2005.

- - - Regulación jurídica de los partidos políticos en América Latina, México, IDEA Internacional-UNAM, Instituto de Investigaciones Jurídicas, 2006.

- - - "El financiamiento electoral: subvenciones y gastos", en NoHLEN, Dieter et al. (eds.), Tratado de derecho electoral comparado de América Latina, México, Fondo de Cultura Económica, 2007. Zovatto Garetto, D. y Orozco, J., Reforma política y electoral en América Latina 1978-2007, México, International IDEA-UNAM, Instituto de Investigaciones Jurídicas, 2008. 